Supplement of Earth Syst. Dynam., 10, 765-788, 2019

https://doi.org/10.5194/esd-10-765-2019-supplement

(C) Author(s) 2019. This work is distributed under

the Creative Commons Attribution 4.0 License.

(c) (1)
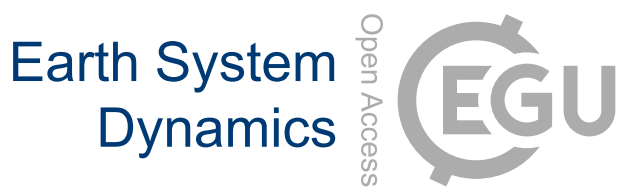

Supplement of

\title{
Changes in statistical distributions of sub-daily surface temperatures and wind speed
}

Robert J. H. Dunn et al.

Correspondence to: Robert J. H. Dunn (robert.dunn@metoffice.gov.uk)

The copyright of individual parts of the supplement might differ from the CC BY 4.0 License. 


\section{Supplementary Information}

\subsection{Further technical details}

We present a few of the data selection analysis aspects in more detail than in the main manuscript, for clarity.

\subsubsection{Zonal}

The climatology for each day of the year is calculated as

$C_{d}=\frac{\sum_{y=1981}^{2010} \sum_{h} O_{y, d, h}}{N_{o b s}}$

where $O_{d}$ are the observations for year $y$, day $d$ and hour $h$, and $N_{o b s}$ are the total number of observations. At least 15 years of 3-hourly observations (total of 8 observations per day) are required for a climatology to be calculated. As this analysis splits the 24 period into day and night, this requirement is at least $N_{o b s} \geq 60$ observations over the 30 year period. The anomalies at each time point are then calculated as $A_{y, d, h}=O_{y, d, h}-C_{d}$ using the daily anomaly for all obser- 15 vations for that day of the year.

For stations to be included in each 5-year interval, we require there to be more observations than the number equivalent to hourly observations for $1 / 4$ of the 5 -year interval for the half-day being assessed:

5 years $\times 365$ days $\times 12$ hours $\div 4=5475$ observations

Furthermore, 3/4 of the 9 intervals (7) are required to have this number of observations present for the station to be included.

\subsubsection{Station based changes}

The climatology for each day of the year is calculated as

$C_{d, h}=\frac{\sum_{y=1981}^{2010} O_{y, d, h}}{N_{o b s}}$

where $O_{y, d, h}$ are all observations for year $y$, day $d$ and hour $h$, and $N_{o b s}$ are the total number of observations. At least 15 years of 3-hourly observations (total of 8 observa- 30 tions per day) are required for a climatology to be calculated, and so $N_{o b s} \geq 15$ observations over the 30 year period. The anomalies at each time point are then calculated as $A_{y, d, h}=O_{y, d, h}-C_{d, h}$ using the hourly anomaly for all observations for that hour of day of the year.

\subsubsection{Quantile Regression}

Daily means were calculated as

$D_{y, d}=\frac{\sum_{h=00: 00}^{23: 00} O_{y, d, h}}{N_{o b s}}$ where $N_{o b s} \geq 8$ (the equivalent of 3-hourly data). These were then used to calculate the daily climatology

$C_{d}=\frac{\sum_{y=1981}^{2010} D_{y, d}}{N_{d}}$

where $O_{y, d, h}$ are all observations for year $y$, day $d$ and hour $5 h$, and $N_{d}$ are the total number of days. At least 15 years of are required for a climatology to be calculate $\left(N_{d} \geq 15\right)$. The anomalies at each time point are then calculated as $A_{y, d}={ }_{45}$ $D_{y, d}-C_{d}$ using the daily anomaly for all observations for that day of the year.

\subsection{Extra Figures}

Here we show extra figures and tables for different variables, 10 seasons or times of the day for completeness. For ease, in 50 some cases these are reproduced from the main paper to retain a logical flow 


\begin{tabular}{|c|c|c|c|c|c|}
\hline Band & N-stations & Mean $\left({ }^{\circ} \mathrm{C}\right.$ decade $\left.{ }^{-1}\right)$ & $\mathrm{SD}\left({ }^{\circ} \mathrm{C}\right.$ decade $\left.{ }^{-1}\right)$ & Skew $\left(\right.$ decade $\left.^{-1}\right)$ & Kurtosis $\left(\right.$ decade $^{-1}$ ) \\
\hline & \multicolumn{5}{|c|}{ Day } \\
\hline $70 \rightarrow 60$ & 155 & $0.41(0.37 \rightarrow 0.47)$ & $-0.15(-0.17 \rightarrow-0.12)$ & $0.03(0.01 \rightarrow 0.05)$ & $0.04(0.01 \rightarrow 0.09)$ \\
\hline $60 \rightarrow 50$ & 405 & $0.28(0.24 \rightarrow 0.34)$ & $-0.04(-0.09 \rightarrow-0.02)$ & $0.03(0.02 \rightarrow 0.05)$ & $-0.10(-0.17 \rightarrow-0.03)$ \\
\hline $50 \rightarrow 40$ & 407 & $0.20(0.17 \rightarrow 0.26)$ & $-0.07(-0.08 \rightarrow-0.06)$ & $0.03(0.02 \rightarrow 0.06)$ & $-0.08(-0.11 \rightarrow-0.04)$ \\
\hline $40 \rightarrow 30$ & 268 & $0.09(0.05 \rightarrow 0.20)$ & $-0.03(-0.08 \rightarrow 0.01)$ & $0.01(-0.00 \rightarrow 0.01)$ & $0.07(0.04 \rightarrow 0.11)$ \\
\hline $30 \rightarrow 20$ & 103 & $0.19(0.01 \rightarrow 0.21)$ & $0.04(-0.02 \rightarrow 0.06)$ & $0.02(-0.01 \rightarrow 0.06)$ & $0.03(-0.03 \rightarrow 0.08)$ \\
\hline $20 \rightarrow 10$ & 63 & $0.21(0.16 \rightarrow 0.24)$ & $-0.01(-0.03 \rightarrow 0.03)$ & $0.11(0.07 \rightarrow 0.13)$ & $-0.16(-0.21 \rightarrow-0.11)$ \\
\hline $10 \rightarrow 0$ & 22 & $0.17(0.14 \rightarrow 0.19)$ & $0.01(-0.02 \rightarrow 0.04)$ & $-0.08(-0.10 \rightarrow-0.01)$ & $0.43(0.32 \rightarrow 0.65)$ \\
\hline $0 \rightarrow-10$ & 18 & $0.04(0.00 \rightarrow 0.10)$ & $0.01(-0.00 \rightarrow 0.04)$ & $-0.09(-0.15 \rightarrow-0.02)$ & $-0.09(-0.21 \rightarrow 0.09)$ \\
\hline$-10 \rightarrow-20$ & 21 & $0.04(0.01 \rightarrow 0.06)$ & $0.02(0.00 \rightarrow 0.04)$ & $-0.05(-0.11 \rightarrow-0.01)$ & $-0.04(-0.20 \rightarrow 0.18)$ \\
\hline$-20 \rightarrow-30$ & 22 & $0.00(-0.07 \rightarrow 0.12)$ & $-0.05(-0.07 \rightarrow-0.02)$ & $-0.08(-0.10 \rightarrow-0.06)$ & $0.30(0.25 \rightarrow 0.41)$ \\
\hline$-30 \rightarrow-40$ & 24 & $-0.12(-0.16 \rightarrow-0.03)$ & $0.00(-0.04 \rightarrow 0.06)$ & $-0.03(-0.03 \rightarrow-0.01)$ & $0.07(0.05 \rightarrow 0.12)$ \\
\hline \multirow[t]{2}{*}{$-40 \rightarrow-50$} & 5 & $-0.02(-0.05 \rightarrow 0.06)$ & $0.03(0.02 \rightarrow 0.07)$ & $0.00(-0.01 \rightarrow 0.03)$ & $0.04(0.01 \rightarrow 0.08)$ \\
\hline & \multicolumn{5}{|c|}{ Night } \\
\hline $70 \rightarrow 60$ & 127 & $0.44(0.35 \rightarrow 0.57)$ & $-0.14(-0.17 \rightarrow-0.12)$ & $0.02(0.00 \rightarrow 0.04)$ & $0.04(-0.00 \rightarrow 0.12)$ \\
\hline $60 \rightarrow 50$ & 363 & $0.31(0.25 \rightarrow 0.36)$ & $-0.04(-0.08 \rightarrow-0.02)$ & $0.03(0.01 \rightarrow 0.05)$ & $-0.13(-0.13 \rightarrow-0.00)$ \\
\hline $50 \rightarrow 40$ & 358 & $0.29(0.26 \rightarrow 0.35)$ & $-0.12(-0.13 \rightarrow-0.11)$ & $0.05(0.03 \rightarrow 0.07)$ & $-0.07(-0.11 \rightarrow-0.03)$ \\
\hline $40 \rightarrow 30$ & 211 & $0.19(0.17 \rightarrow 0.31)$ & $-0.08(-0.14 \rightarrow-0.02)$ & $0.03(0.01 \rightarrow 0.06)$ & $0.06(0.03 \rightarrow 0.12)$ \\
\hline $30 \rightarrow 20$ & 54 & $0.22(0.11 \rightarrow 0.28)$ & $0.00(-0.03 \rightarrow 0.05)$ & $0.02(0.00 \rightarrow 0.05)$ & $0.08(-0.03 \rightarrow 0.11)$ \\
\hline $20 \rightarrow 10$ & 33 & $0.24(0.19 \rightarrow 0.26)$ & $-0.03(-0.06 \rightarrow-0.00)$ & $0.13(0.12 \rightarrow 0.20)$ & $-0.29(-0.37 \rightarrow-0.18)$ \\
\hline $10 \rightarrow 0$ & 9 & $0.22(0.20 \rightarrow 0.25)$ & $-0.01(-0.03 \rightarrow 0.01)$ & $0.14(0.10 \rightarrow 0.17)$ & $-0.48(-0.81 \rightarrow-0.33)$ \\
\hline $0 \rightarrow-10$ & 8 & $0.08(0.08 \rightarrow 0.12)$ & $-0.04(-0.06 \rightarrow-0.02)$ & $0.02(-0.10 \rightarrow 0.08)$ & $-0.12(-0.38 \rightarrow 0.43)$ \\
\hline$-10 \rightarrow-20$ & 5 & $0.08(0.06 \rightarrow 0.15)$ & $-0.01(-0.05 \rightarrow 0.04)$ & $0.08(-0.03 \rightarrow 0.15)$ & $-0.20(-0.43 \rightarrow-0.05)$ \\
\hline$-20 \rightarrow-30$ & 13 & $0.14(0.05 \rightarrow 0.18)$ & $-0.00(-0.03 \rightarrow 0.02)$ & $-0.03(-0.05 \rightarrow-0.02)$ & $0.15(0.09 \rightarrow 0.23)$ \\
\hline$-30 \rightarrow-40$ & 15 & $0.02(-0.02 \rightarrow 0.06)$ & $-0.05(-0.07 \rightarrow 0.01)$ & $-0.04(-0.05 \rightarrow-0.01)$ & $0.06(0.04 \rightarrow 0.11)$ \\
\hline$-40 \rightarrow-50$ & 4 & $0.11(0.10 \rightarrow 0.18)$ & $0.01(0.00 \rightarrow 0.06)$ & $0.03(0.03 \rightarrow 0.04)$ & $-0.15(-0.20 \rightarrow-0.10)$ \\
\hline
\end{tabular}

Table S1. Fits to parameters in zonal analysis for TOP day-, and вотTOM night-time dewpoint temperature observations. Values in bold show parameters and bands where the $1 \sigma$ range of the fitted trend does not include zero. 

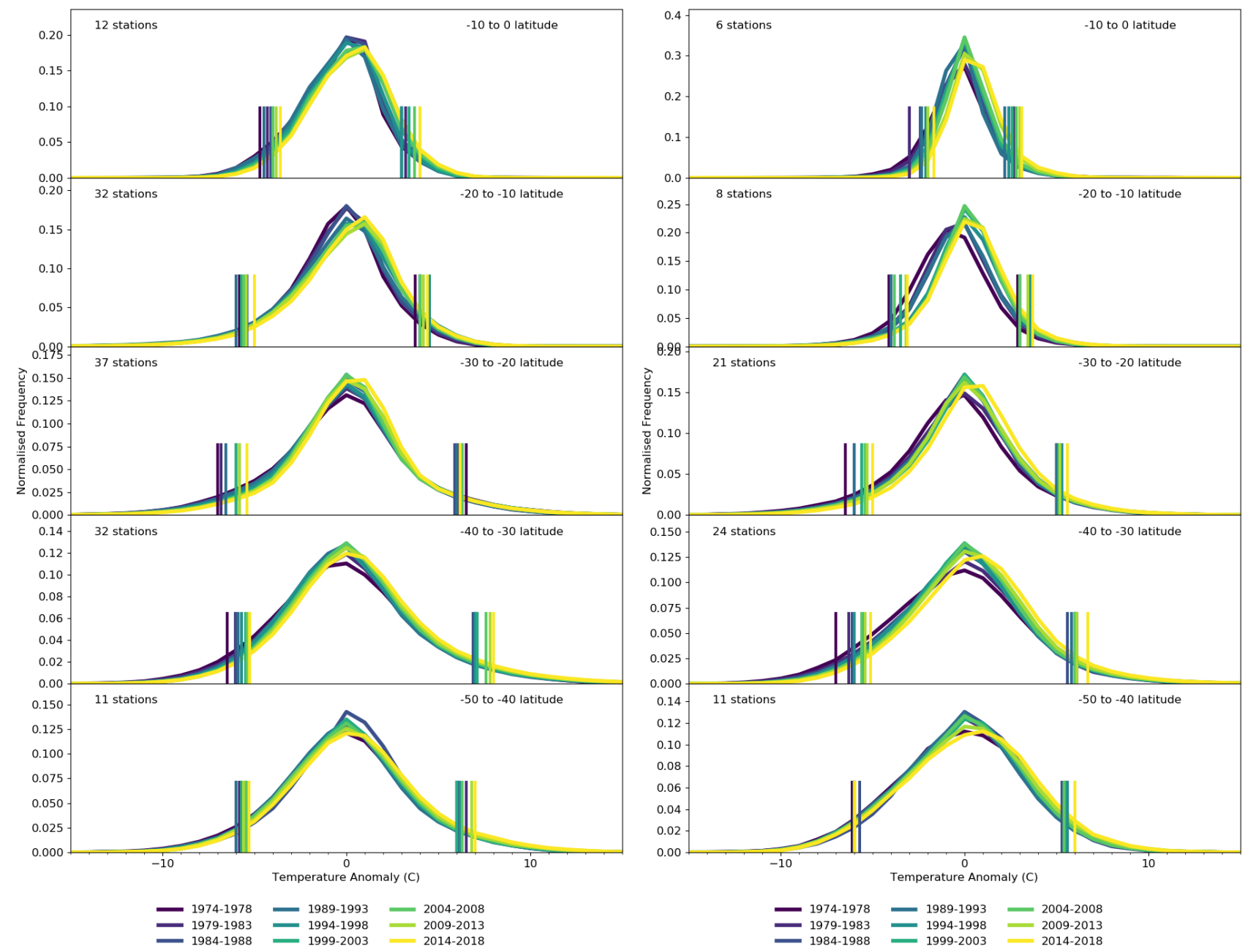

Figure S1. Temperature distributions in latitudinal bands for LEFT day and RIGHT night time observations for the southern hemisphere. 

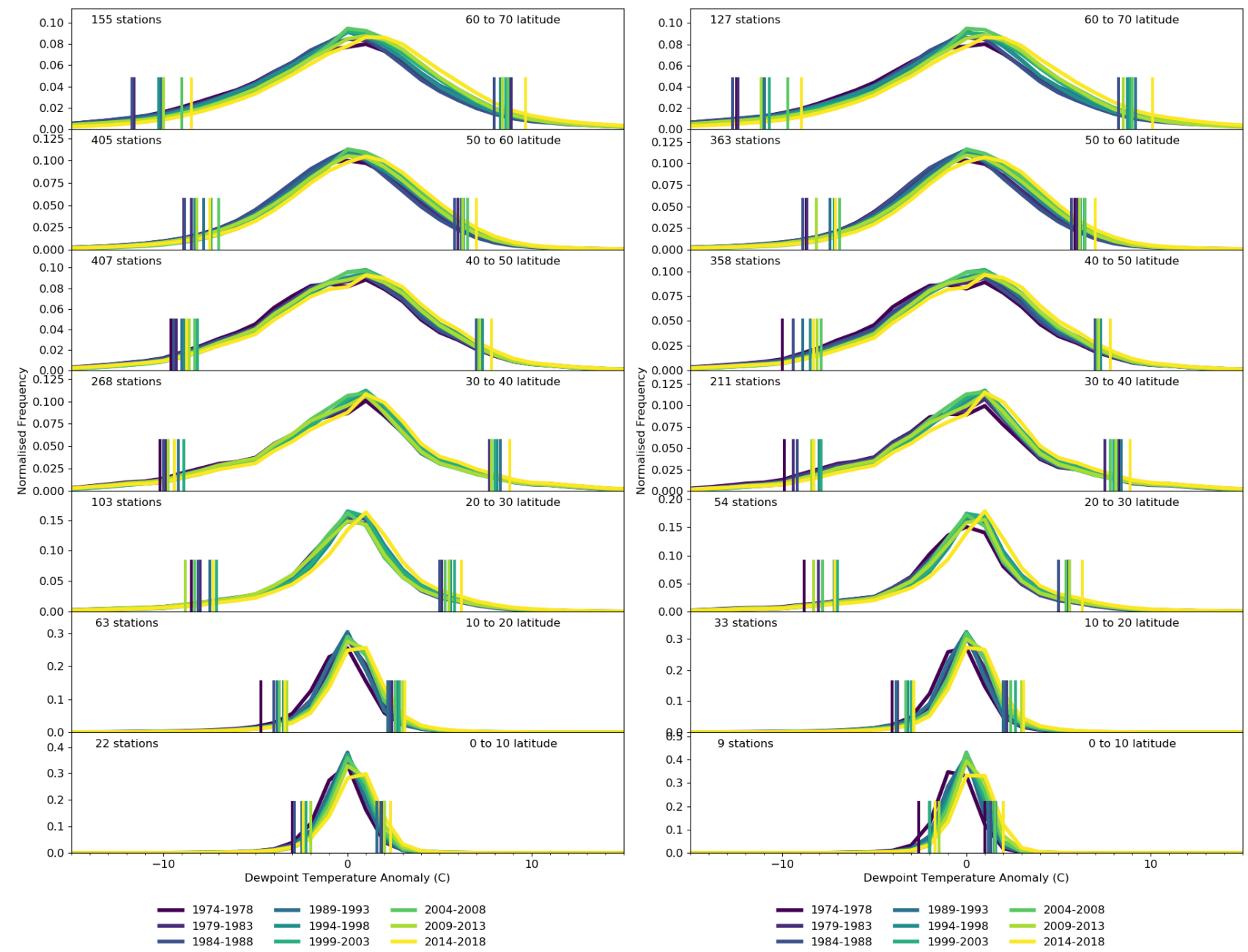

Figure S2. Dewpoint temperature distributions in latitudinal bands for LEFT day and RIGHT night time observations for the northern hemisphere. 

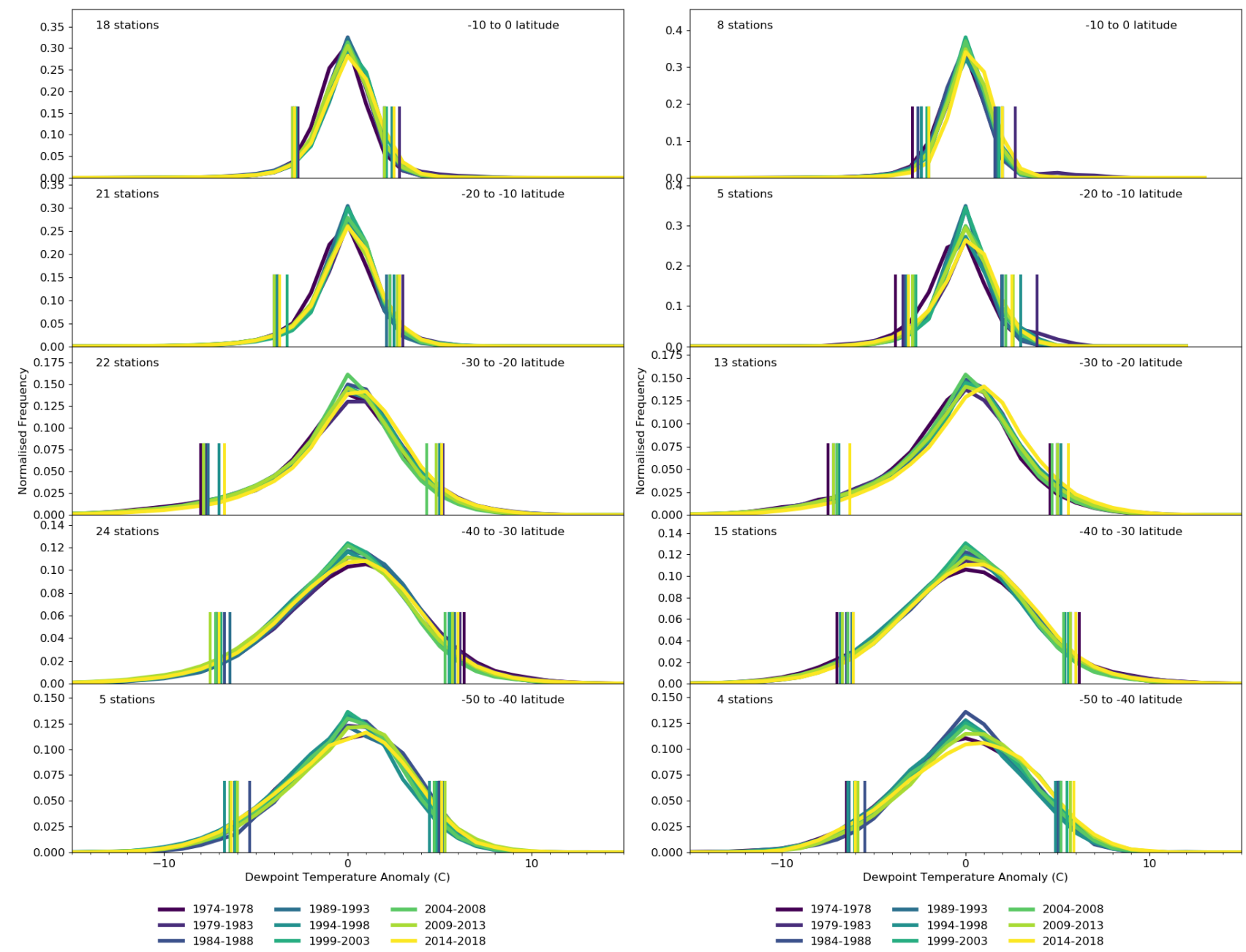

Figure S3. Dewpoint temperature distributions in latitudinal bands for LEFT day and RIGHT night time observations for the southern hemisphere. 


\begin{tabular}{|c|c|c|c|c|c|}
\hline Band & N-stations & Mean $\left(\mathrm{m} \mathrm{s}^{-1}\right.$ decade $\left.^{-1}\right)$ & $\mathrm{SD}\left(\mathrm{m} \mathrm{s}^{-1}\right.$ decade $\left.^{-1}\right)$ & Skew (decade ${ }^{-1}$ ) & Kurtosis $\left(\right.$ decade $\left.^{-1}\right)$ \\
\hline & \multicolumn{5}{|c|}{ Day } \\
\hline $70 \rightarrow 60$ & 111 & $-0.07(-0.08 \rightarrow-0.01)$ & $-0.03(-0.03 \rightarrow-0.01)$ & $-0.01(-0.04 \rightarrow 0.03)$ & $-0.19(-0.92 \rightarrow 0.03)$ \\
\hline $60 \rightarrow 50$ & 243 & $-0.12(-0.13 \rightarrow-0.08)$ & $-0.07(-0.08 \rightarrow-0.06)$ & $0.03(0.02 \rightarrow 0.04)$ & $0.41(0.29 \rightarrow 0.46)$ \\
\hline $50 \rightarrow 40$ & 381 & $-0.09(-0.09 \rightarrow-0.07)$ & $-0.02(-0.02 \rightarrow-0.01)$ & $0.01(0.00 \rightarrow 0.02)$ & $0.05(-0.06 \rightarrow 0.33)$ \\
\hline $40 \rightarrow 30$ & 233 & $-0.05(-0.06 \rightarrow-0.04)$ & $0.01(-0.00 \rightarrow 0.03)$ & $0.01(-0.02 \rightarrow 0.04)$ & $-0.15(-0.28 \rightarrow-0.01)$ \\
\hline $30 \rightarrow 20$ & 83 & $-0.04(-0.06 \rightarrow-0.03)$ & $-0.01(-0.01 \rightarrow 0.00)$ & $0.00(-0.07 \rightarrow 0.05)$ & $-0.32(-0.74 \rightarrow 0.30)$ \\
\hline $20 \rightarrow 10$ & 27 & $-0.07(-0.09 \rightarrow-0.05)$ & $-0.04(-0.05 \rightarrow 0.00)$ & $-0.23(-0.32 \rightarrow-0.15)$ & $-3.98(-4.82 \rightarrow-2.53)$ \\
\hline \multirow[t]{2}{*}{$10 \rightarrow 0$} & 13 & $-0.01(-0.04 \rightarrow 0.02)$ & $-0.10(-0.11 \rightarrow-0.08)$ & $-0.28(-0.30 \rightarrow-0.20)$ & $-4.09(-4.35 \rightarrow-1.99)$ \\
\hline & \multicolumn{5}{|c|}{ Night } \\
\hline $70 \rightarrow 60$ & 93 & $-0.06(-0.07 \rightarrow 0.00)$ & $-0.03(-0.04 \rightarrow-0.01)$ & $0.00(-0.03 \rightarrow 0.04)$ & $-0.17(-0.75 \rightarrow 0.38)$ \\
\hline $60 \rightarrow 50$ & 215 & $-0.10(-0.12 \rightarrow-0.06)$ & $-0.08(-0.08 \rightarrow-0.07)$ & $0.01(0.00 \rightarrow 0.02)$ & $0.18(0.06 \rightarrow 0.38)$ \\
\hline $50 \rightarrow 40$ & 331 & $-0.07(-0.08 \rightarrow-0.06)$ & $-0.03(-0.03 \rightarrow-0.02)$ & $0.01(-0.01 \rightarrow 0.04)$ & $0.04(-0.04 \rightarrow 0.22)$ \\
\hline $40 \rightarrow 30$ & 184 & $-0.04(-0.05 \rightarrow-0.04)$ & $-0.00(-0.01 \rightarrow 0.00)$ & $0.02(-0.03 \rightarrow 0.05)$ & $-0.02(-0.23 \rightarrow 0.15)$ \\
\hline $30 \rightarrow 20$ & 53 & $-0.05(-0.06 \rightarrow-0.04)$ & $0.01(-0.00 \rightarrow 0.01)$ & $0.04(-0.01 \rightarrow 0.11)$ & $0.37(0.04 \rightarrow 0.97)$ \\
\hline $20 \rightarrow 10$ & 14 & $-0.05(-0.06 \rightarrow-0.02)$ & $0.01(-0.01 \rightarrow 0.03)$ & $-0.26(-0.34 \rightarrow-0.09)$ & $-2.80(-4.03 \rightarrow-2.29)$ \\
\hline $10 \rightarrow 0$ & 6 & $0.06(0.03 \rightarrow 0.08)$ & $-0.05(-0.07 \rightarrow-0.02)$ & $-0.67(-0.96 \rightarrow-0.55)$ & $-12.39(-14.00 \rightarrow-4.79)$ \\
\hline
\end{tabular}

Table S2. Fits to parameters in zonal analysis for тоР day-, and воттом night-time windspeed observations. Values in bold show parameters and bands where the $1 \sigma$ range of the fitted trend does not include zero. 

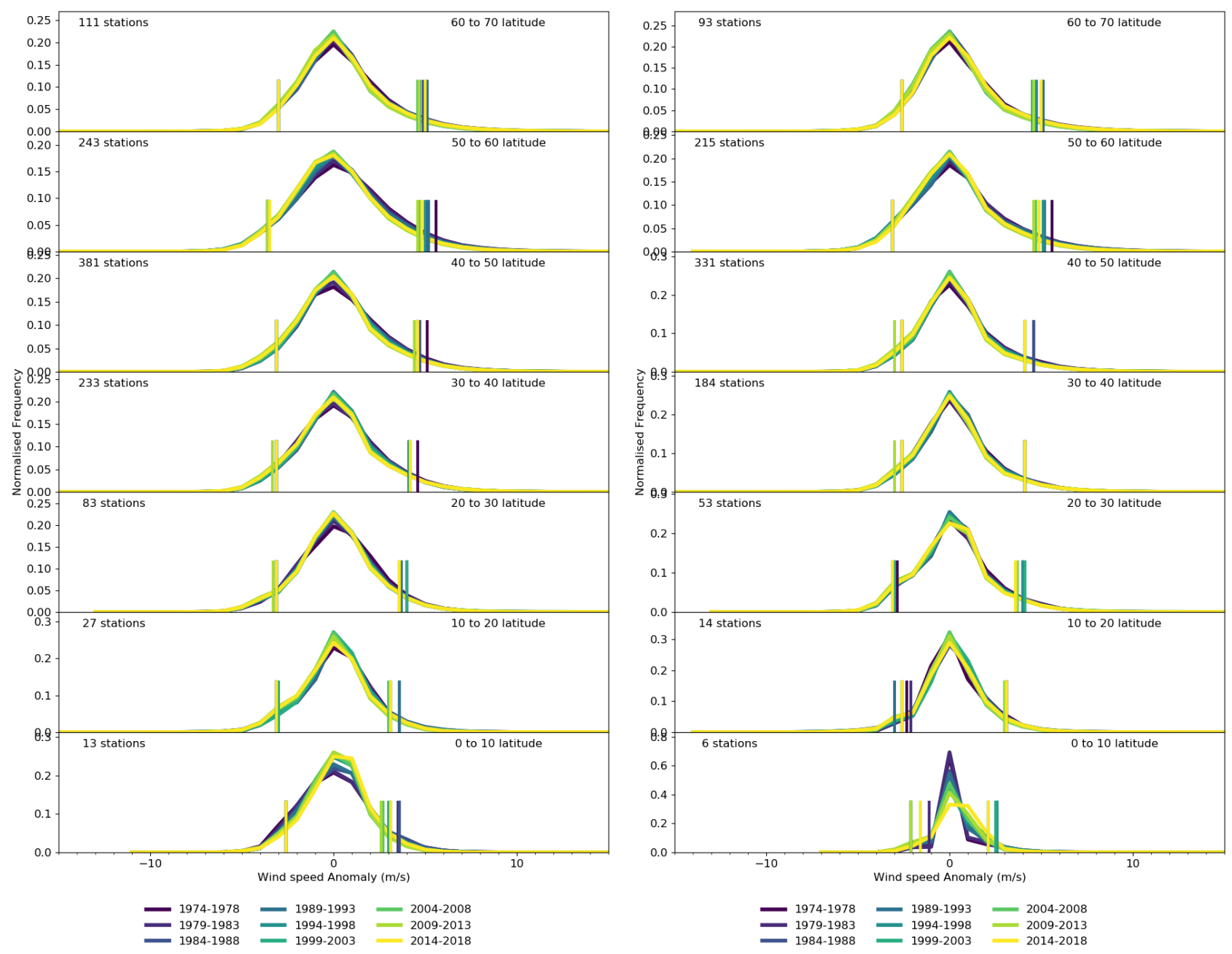

Figure S4. Wind speed distributions in latitudinal bands for LEFT day and RIGHT night time observations for the northern hemisphere. 

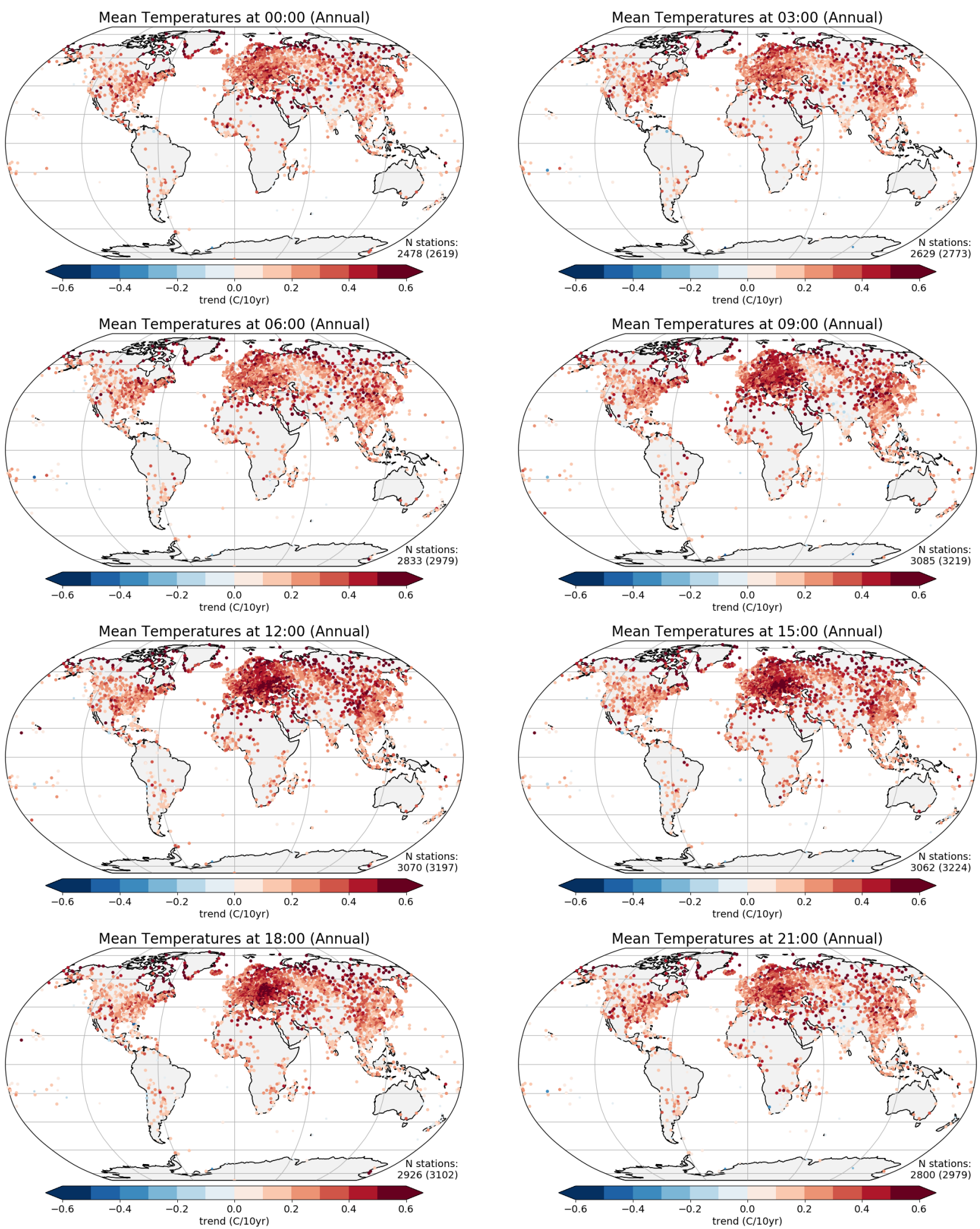

Figure S5. Trend over 1974-2018 in distribution mean for temperature at each three hourly interval. The stations where the $1 \hat{\sigma}$ range of the fitted trend excludes zero are plotted with a larger symbol (the number of these is shown in the bottom right hand corner of each plot). The total number of stations available is shown in parentheses. 

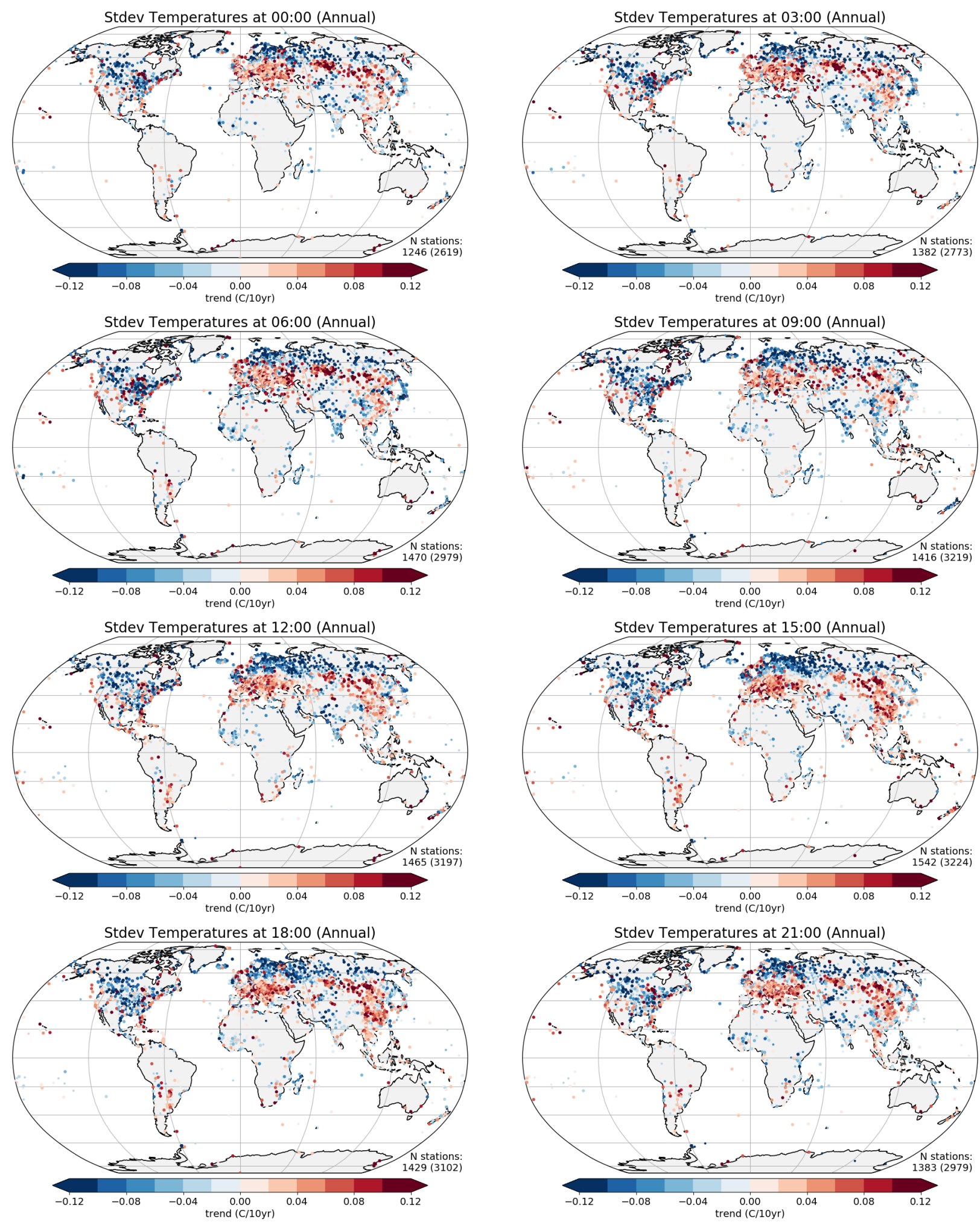

Figure S6. Trend over 1974-2018 in distribution standard deviation for temperature at each three hourly interval. The stations where the $1 \hat{\sigma}$ range of the fitted trend excludes zero are plotted with a larger symbol (the number of these is shown in the bottom right hand corner of each plot). The total number of stations available is shown in parentheses. 

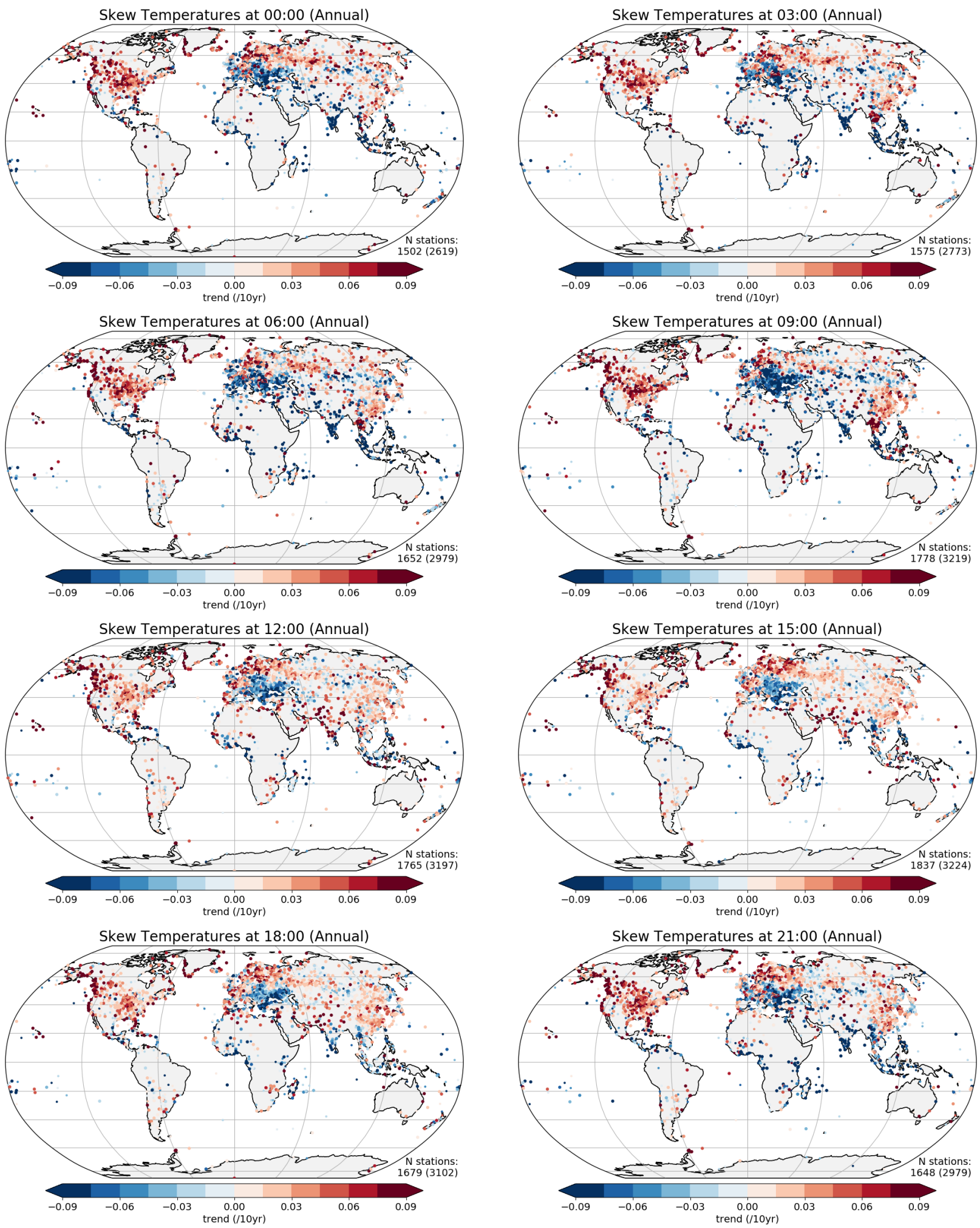

Figure S7. Trend over 1974-2018 in distribution skewness for temperature at each three hourly interval. The stations where the $1 \hat{\sigma}$ range of the fitted trend excludes zero are plotted with a larger symbol (the number of these is shown in the bottom right hand corner of each plot). The total number of stations available is shown in parentheses. 

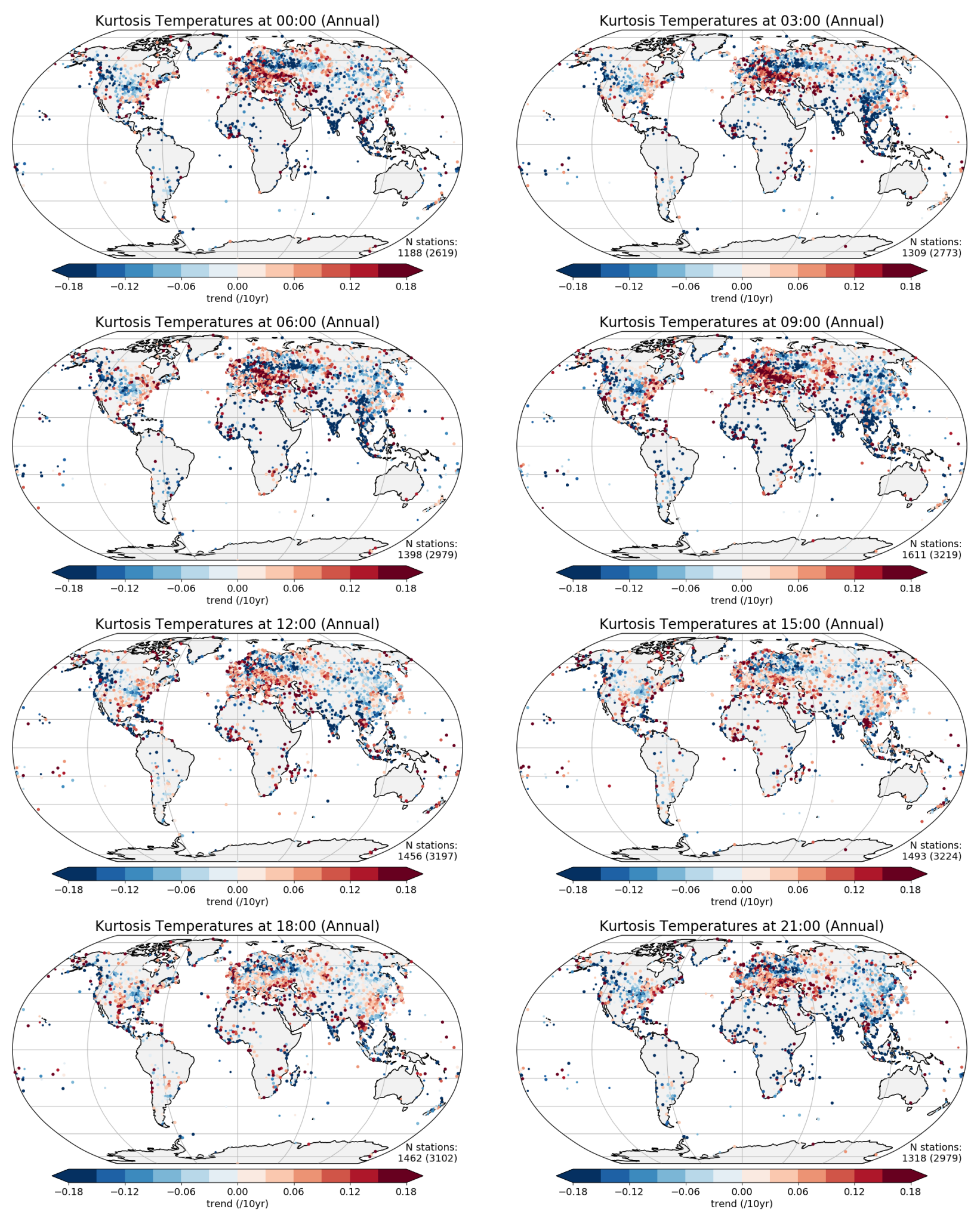

Figure S8. Trend over 1974-2018 in distribution kurtosis for temperature at each three hourly interval. The stations where the $1 \hat{\sigma}$ range of the fitted trend excludes zero are plotted with a larger symbol (the number of these is shown in the bottom right hand corner of each plot). The total number of stations available is shown in parentheses. 

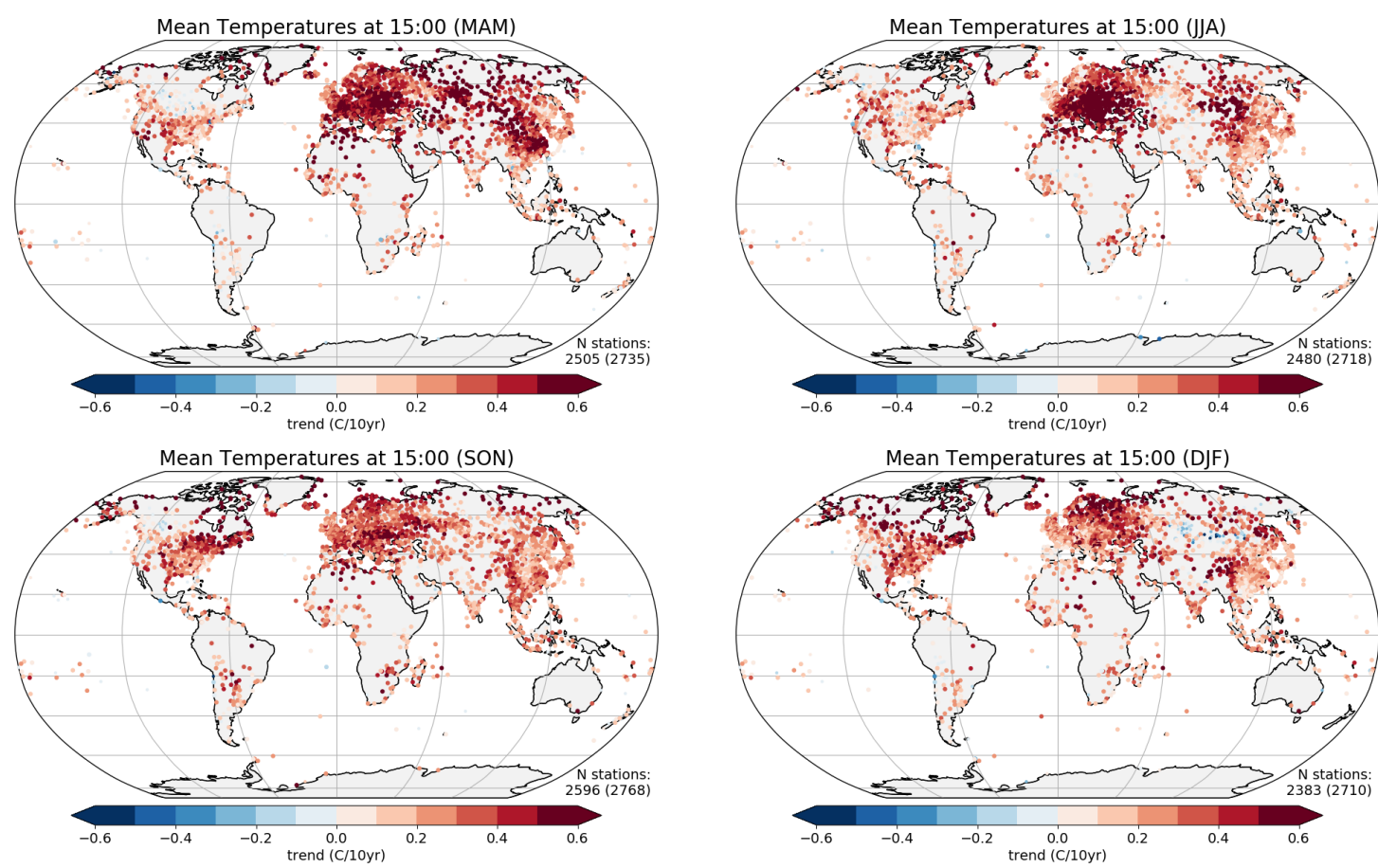

Figure S9. Trend over 1974-2018 in distribution mean for temperature at 1500 local time across the four seasons. The stations where the $1 \hat{\sigma}$ range of the fitted trend excludes zero are plotted with a larger symbol (the number of these is shown in the bottom right hand corner of each plot). The total number of stations available is shown in parentheses.
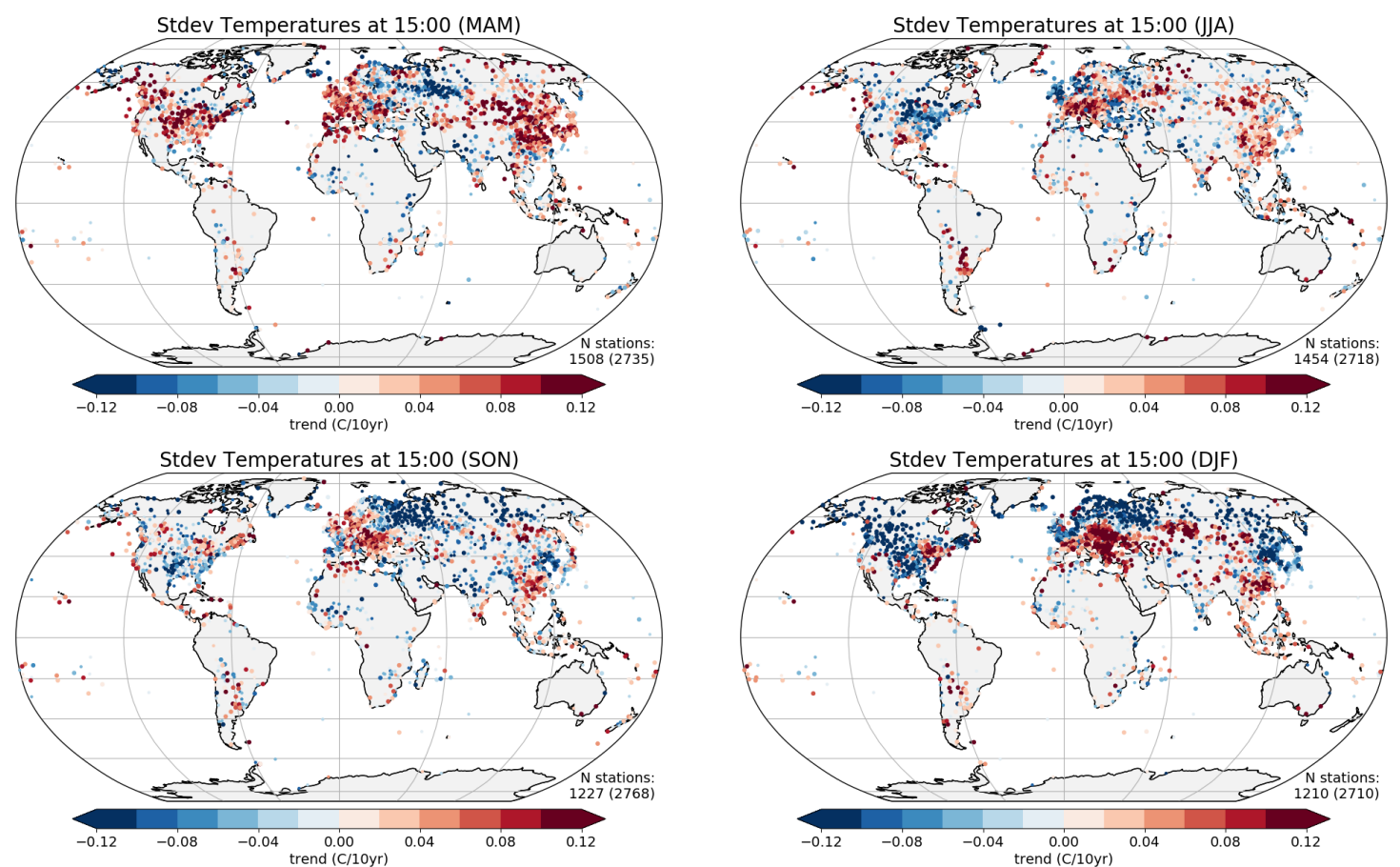

Figure S10. Trend over 1974-2018 in distribution standard deviation for temperature at 1500 local time across the four seasons. The stations where the $1 \hat{\sigma}$ range of the fitted trend excludes zero are plotted with a larger symbol (the number of these is shown in the bottom right hand corner of each plot). The total number of stations available is shown in parentheses. 

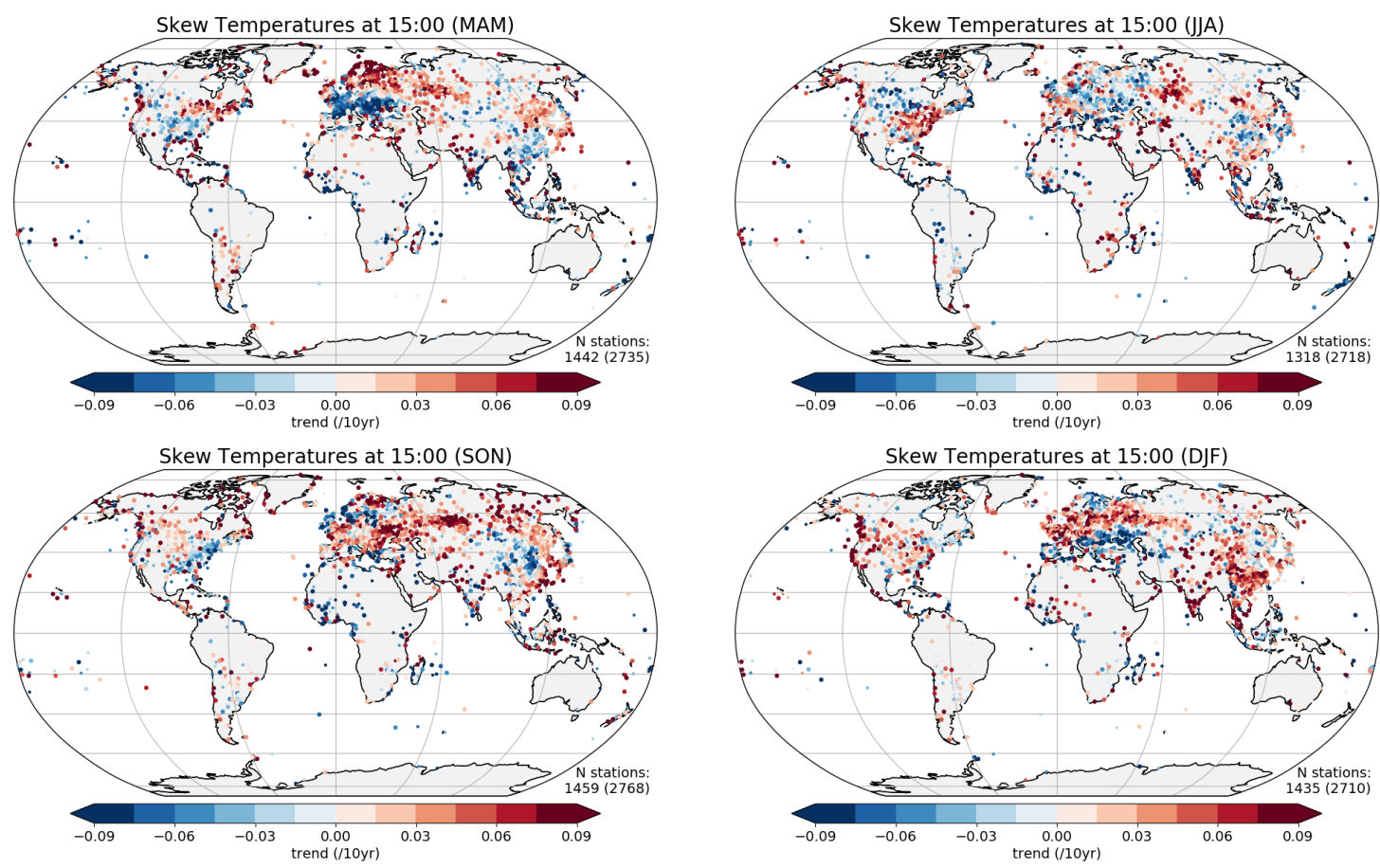

Figure S11. Trend over 1974-2018 in distribution skew for temperature at 1500 local time across the four seasons. The stations where the $1 \hat{\sigma}$ range of the fitted trend excludes zero are plotted with a larger symbol (the number of these is shown in the bottom right hand corner of each plot). The total number of stations available is shown in parentheses.
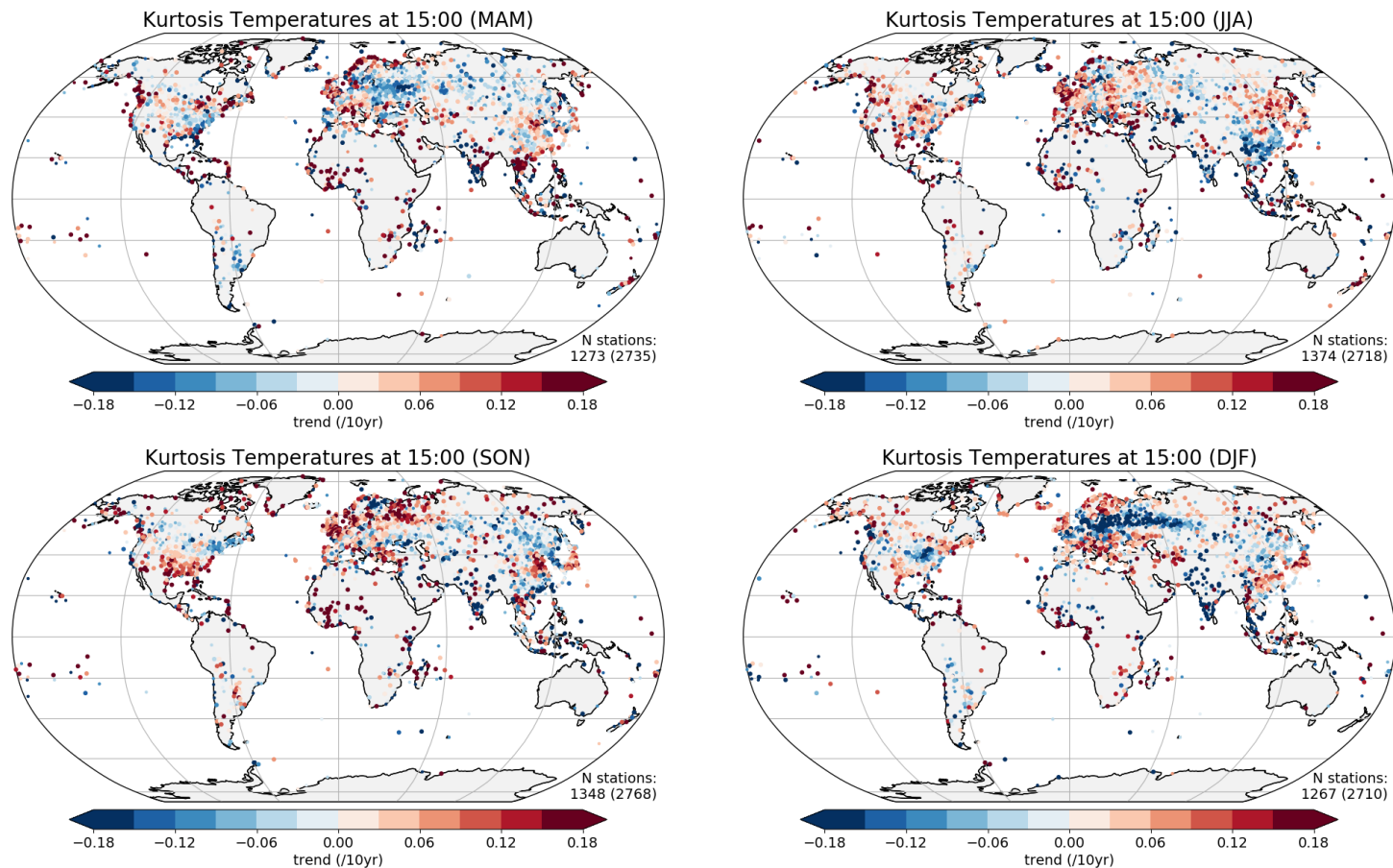

Figure S12. Trend over 1974-2018 in distribution kurtosis for temperature at 1500 local time across the four seasons. The stations where the $1 \hat{\sigma}$ range of the fitted trend excludes zero are plotted with a larger symbol (the number of these is shown in the bottom right hand corner of each plot). The total number of stations available is shown in parentheses. 

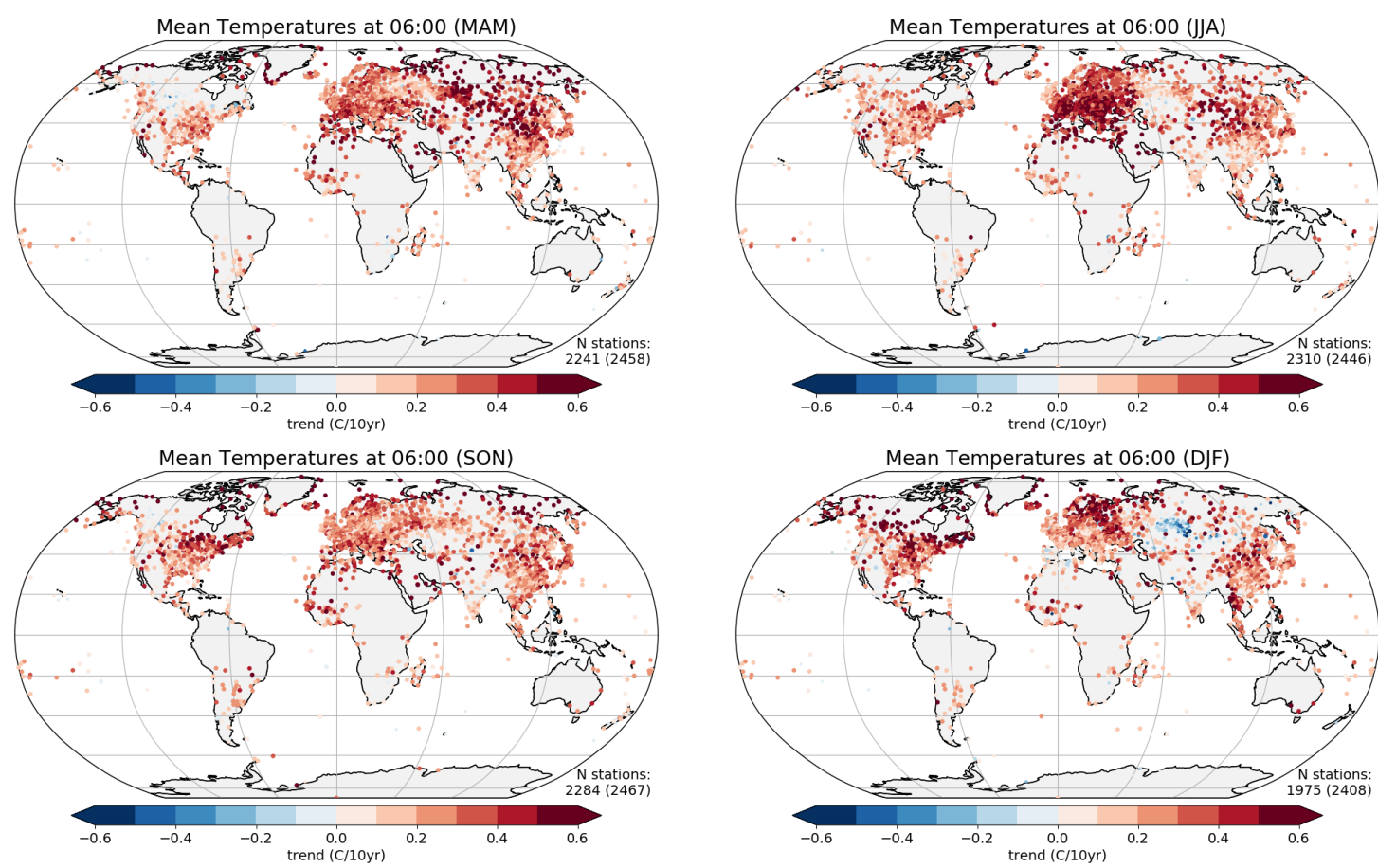

Figure S13. Trend over 1974-2018 in distribution mean for temperature at 0600 local time across the four seasons. The stations where the $1 \hat{\sigma}$ range of the fitted trend excludes zero are plotted with a larger symbol (the number of these is shown in the bottom right hand corner of each plot). The total number of stations available is shown in parentheses.
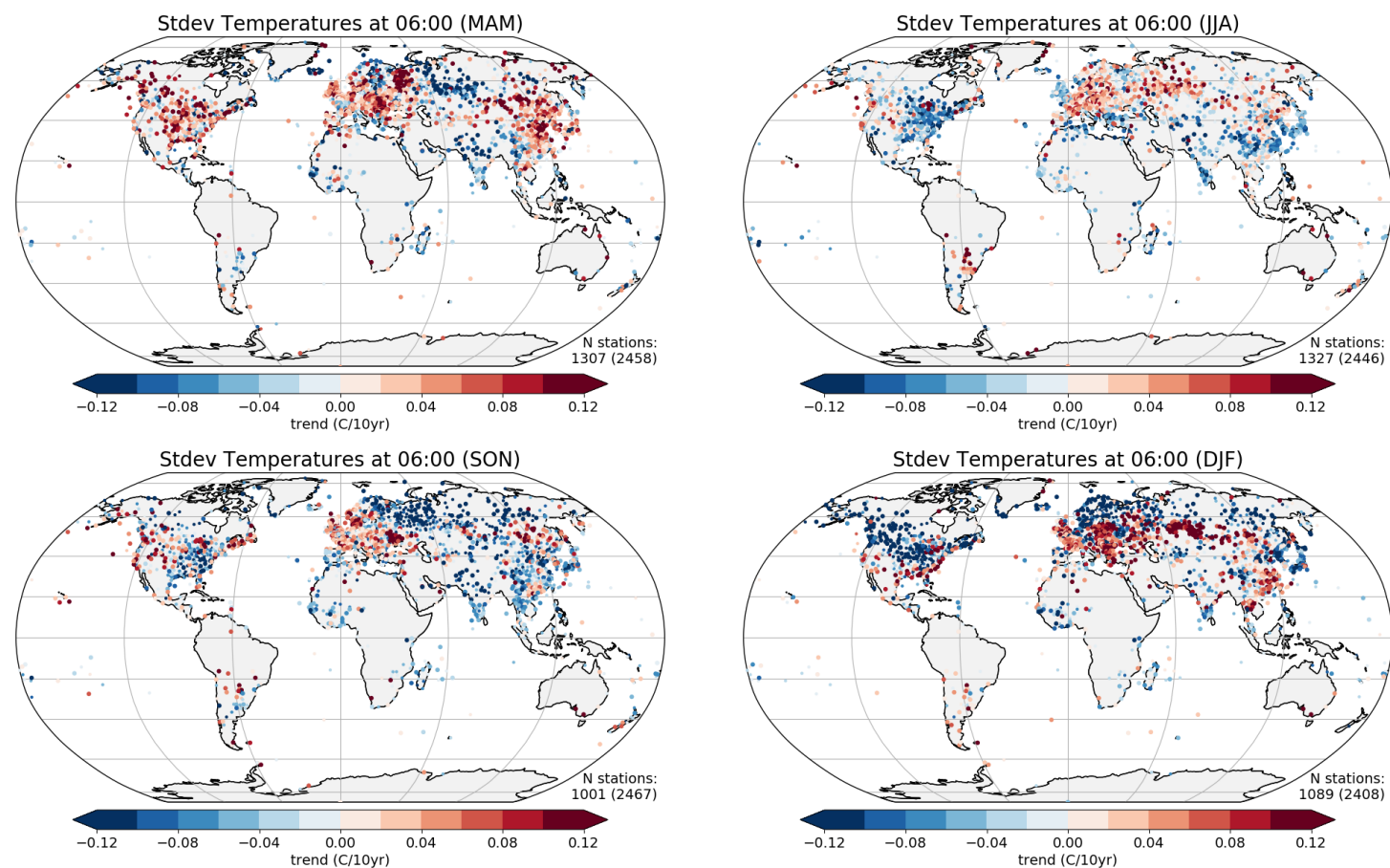

Figure S14. Trend over 1974-2018 in distribution standard deviation for temperature at 0600 local time across the four seasons. The stations where the $1 \hat{\sigma}$ range of the fitted trend excludes zero are plotted with a larger symbol (the number of these is shown in the bottom right hand corner of each plot). The total number of stations available is shown in parentheses. 

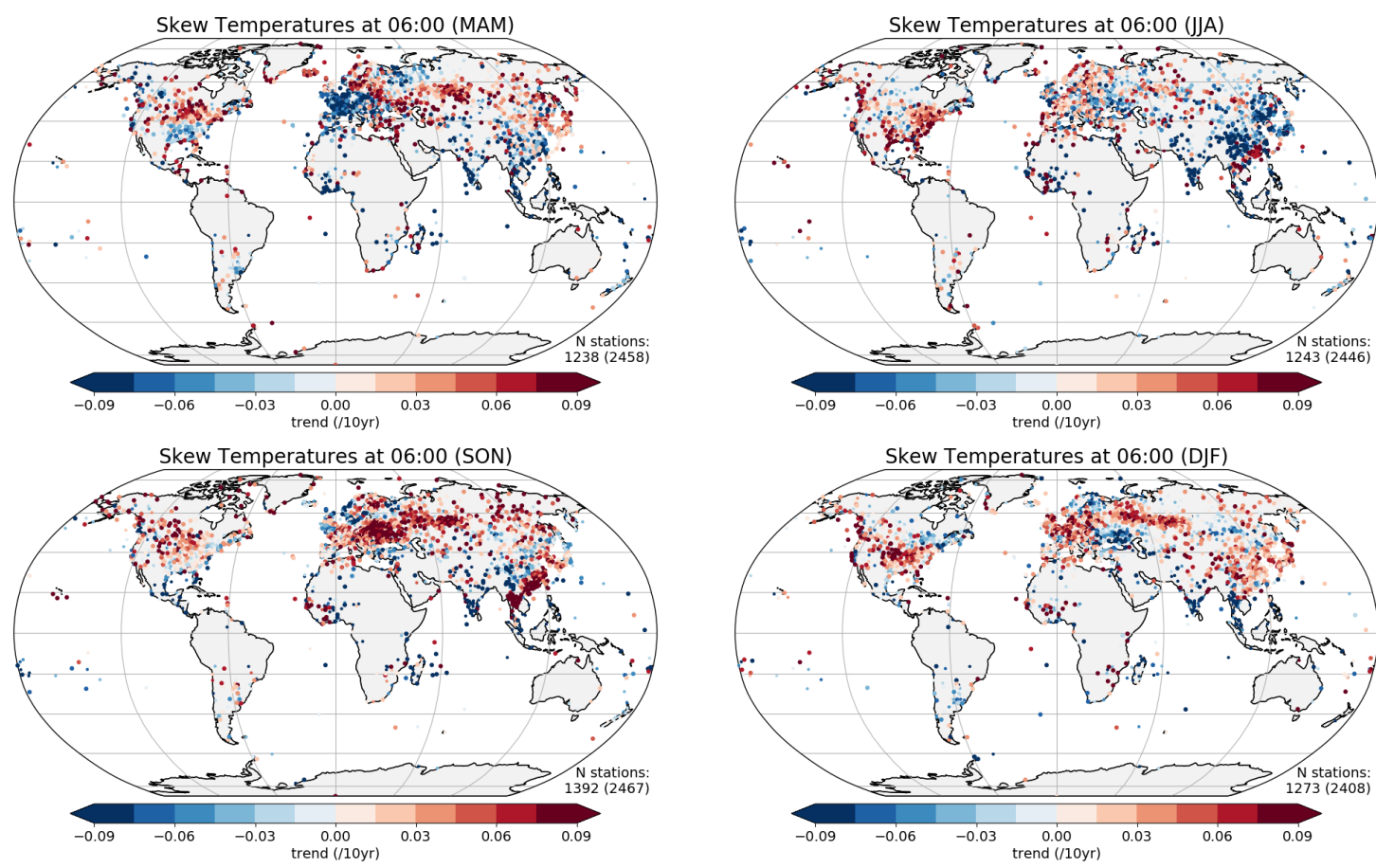

Figure S15. Trend over 1974-2018 in distribution skew for temperature at 0600 local time across the four seasons. The stations where the $1 \hat{\sigma}$ range of the fitted trend excludes zero are plotted with a larger symbol (the number of these is shown in the bottom right hand corner of each plot). The total number of stations available is shown in parentheses.
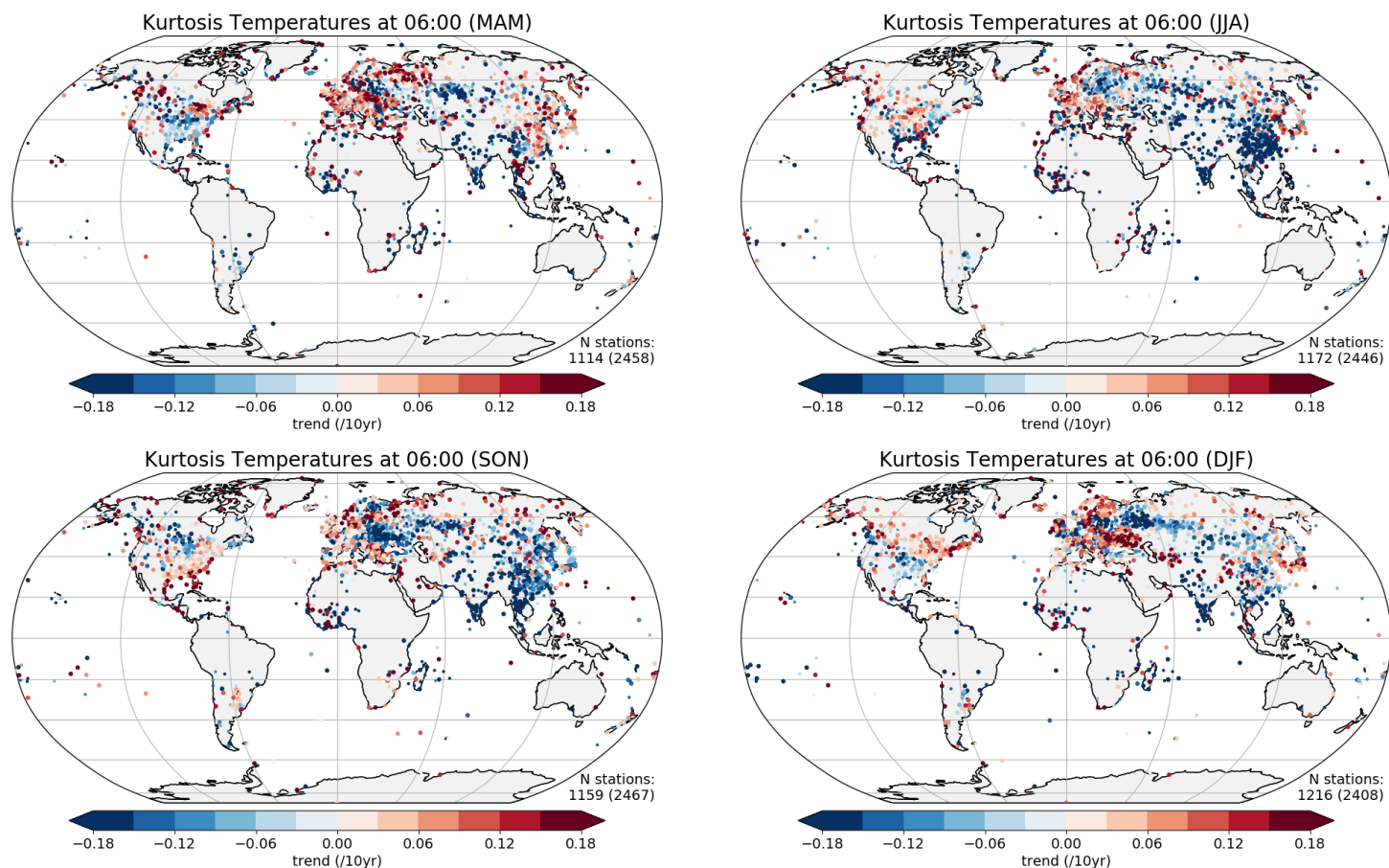

Figure S16. Trend over 1974-2018 in distribution kurtosis for temperature at 0600 local time across the four seasons. The stations where the $1 \hat{\sigma}$ range of the fitted trend excludes zero are plotted with a larger symbol (the number of these is shown in the bottom right hand corner of each plot). The total number of stations available is shown in parentheses. 

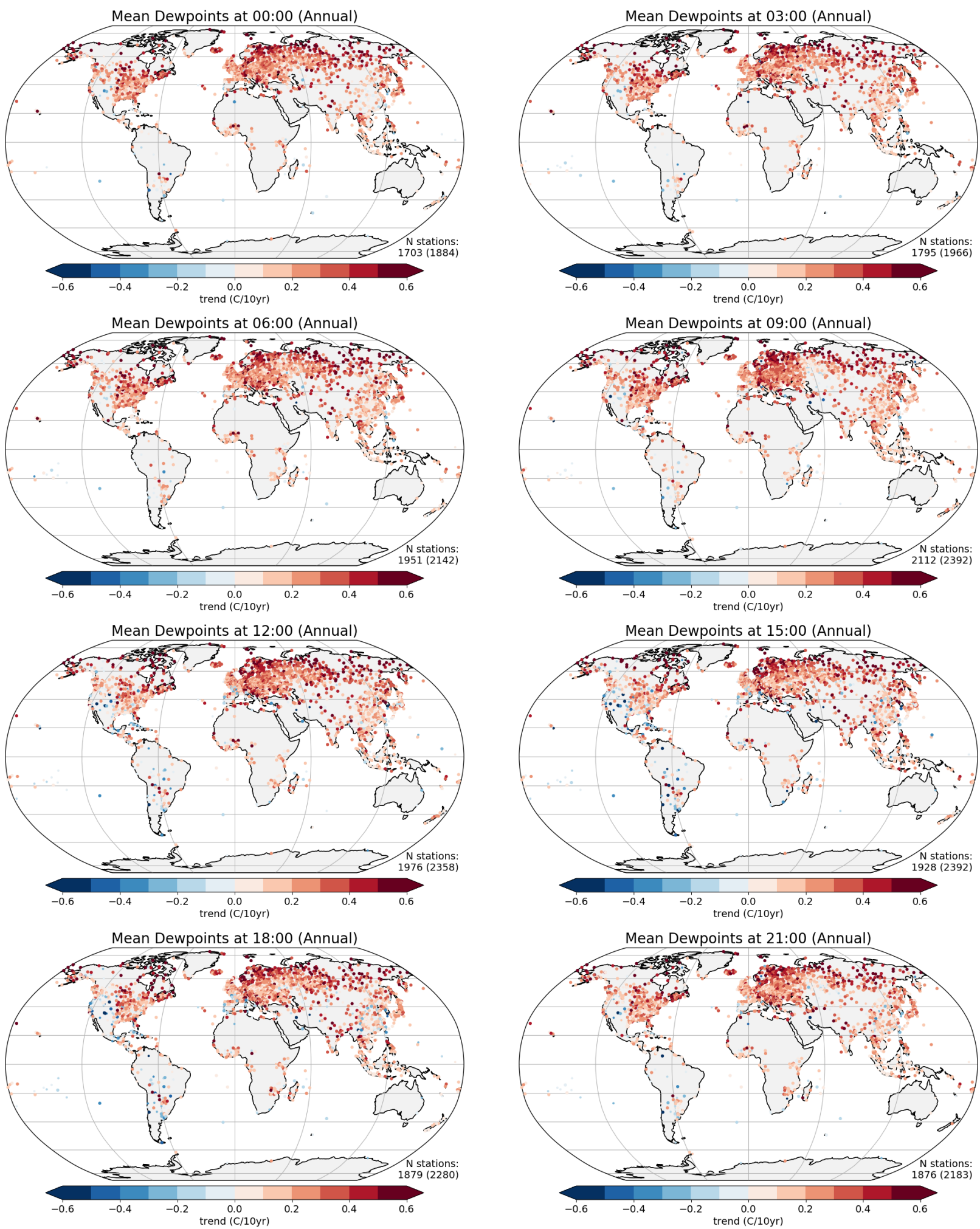

Figure S17. Trend over 1974-2018 in distribution mean for dewpoint temperature at each three hourly interval. The stations where the $1 \hat{\sigma}$ range of the fitted trend excludes zero are plotted with a larger symbol (the number of these is shown in the bottom right hand corner of each plot). The total number of stations available is shown in parentheses. 

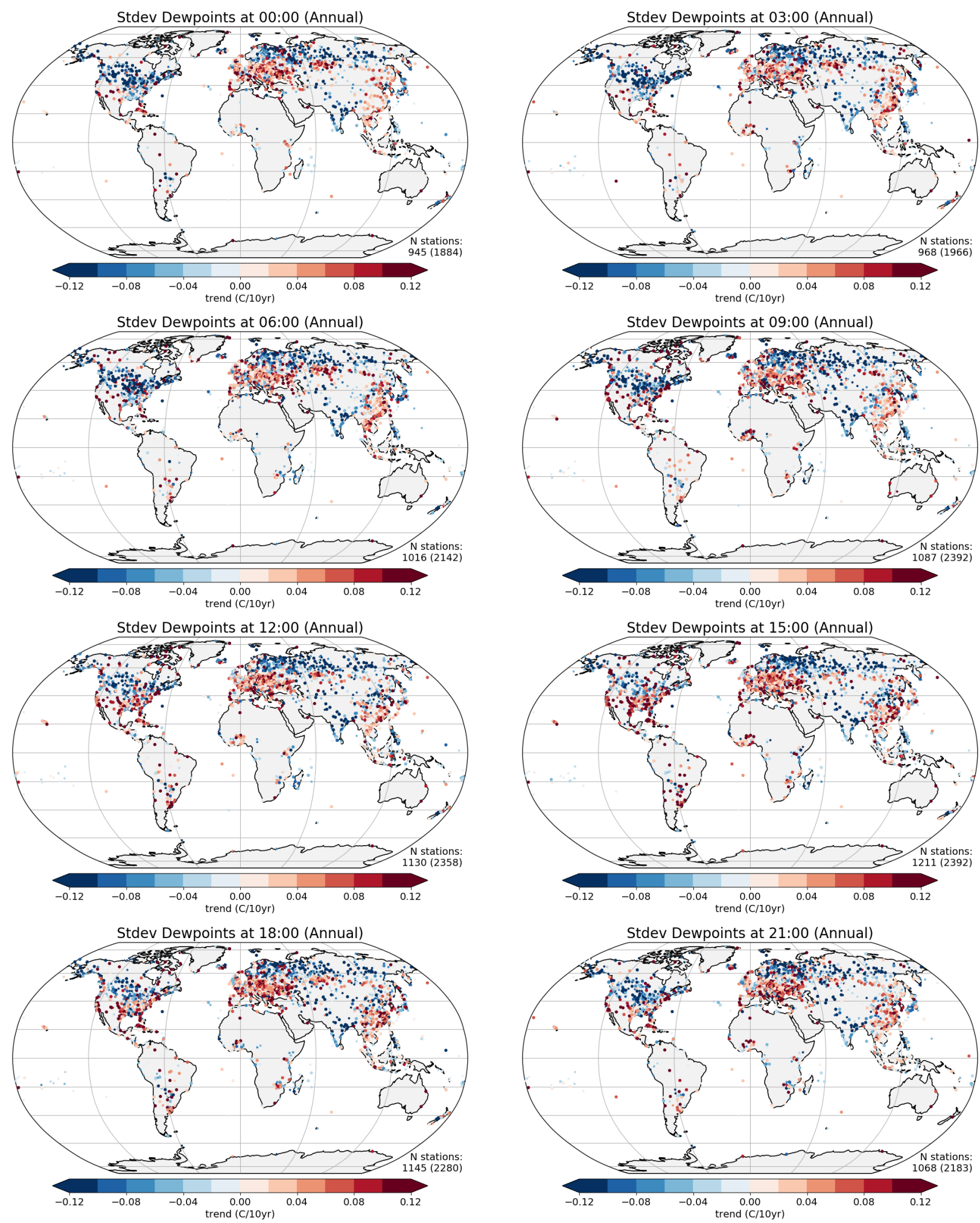

Figure S18. Trend over 1974-2018 in distribution standard deviation for dewpoint temperature at each three hourly interval. The stations where the $1 \hat{\sigma}$ range of the fitted trend excludes zero are plotted with a larger symbol (the number of these is shown in the bottom right hand corner of each plot). The total number of stations available is shown in parentheses. 

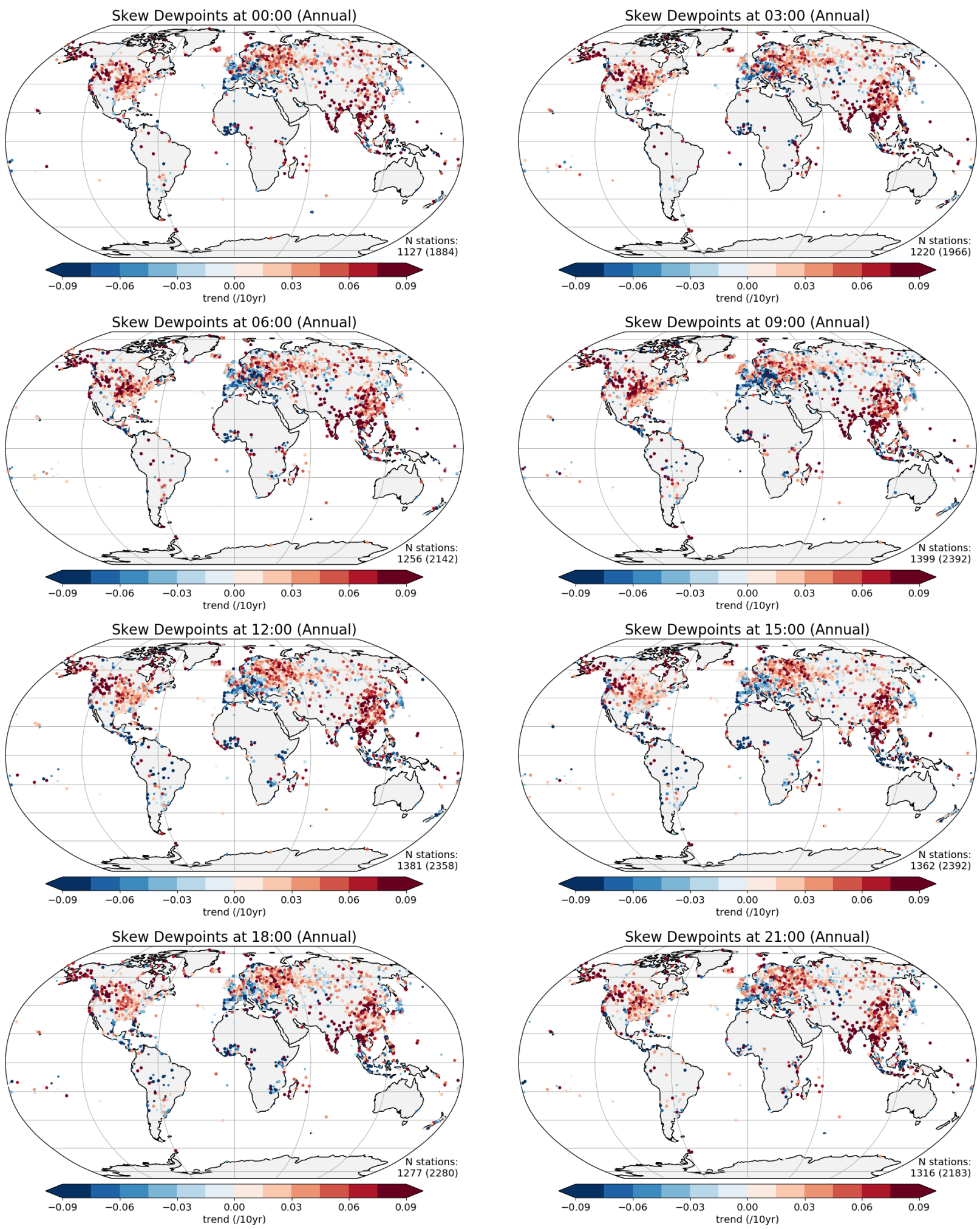

Figure S19. Trend over 1974-2018 in distribution skewness for dewpoint temperature at each three hourly interval. The stations where the $1 \hat{\sigma}$ range of the fitted trend excludes zero are plotted with a larger symbol (the number of these is shown in the bottom right hand corner of each plot). The total number of stations available is shown in parentheses. 

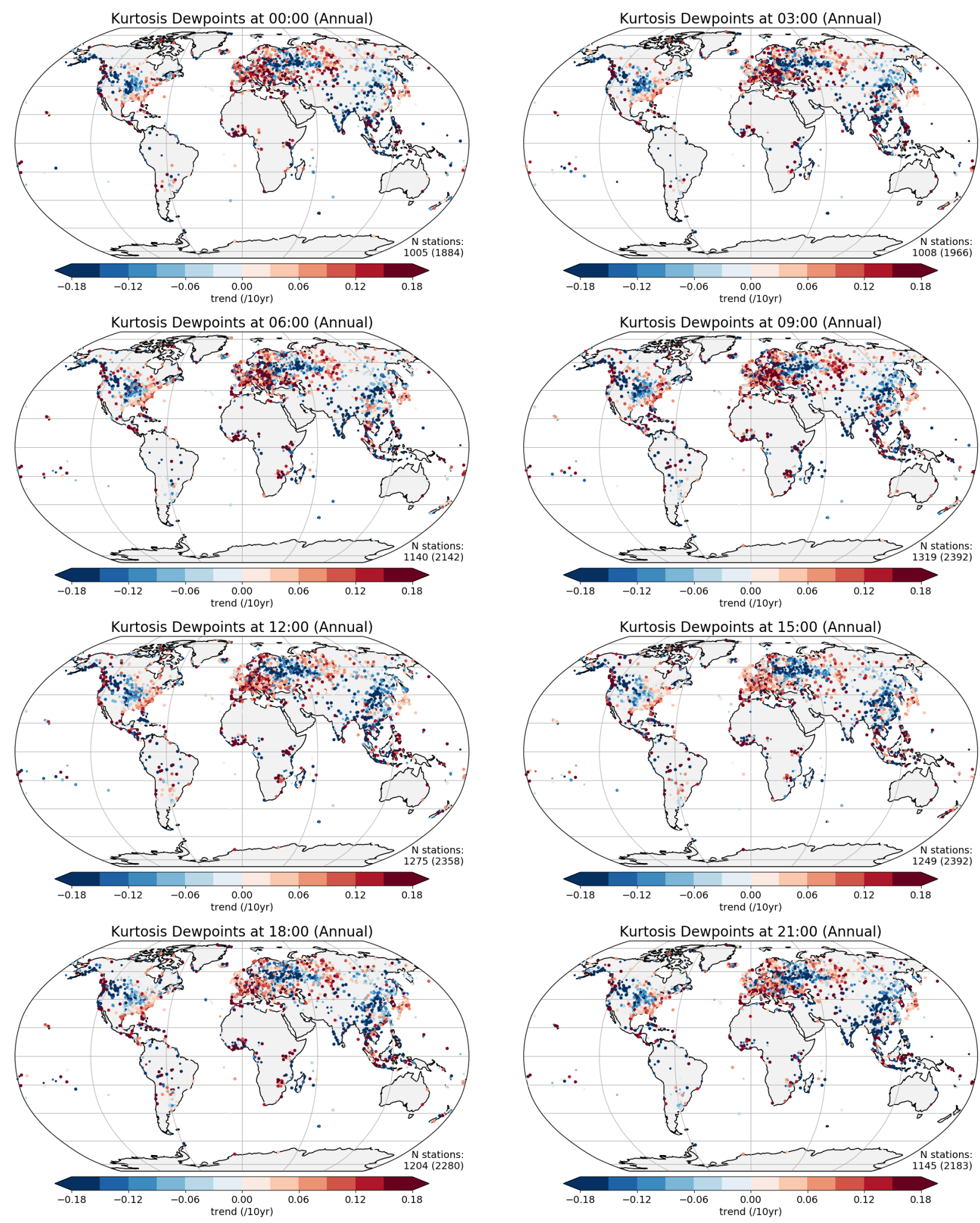

Figure S20. Trend over 1974-2018 in distribution kurtosis for dewpoint temperature at each three hourly interval. The stations where the $1 \hat{\sigma}$ range of the fitted trend excludes zero are plotted with a larger symbol (the number of these is shown in the bottom right hand corner of each plot). The total number of stations available is shown in parentheses. 

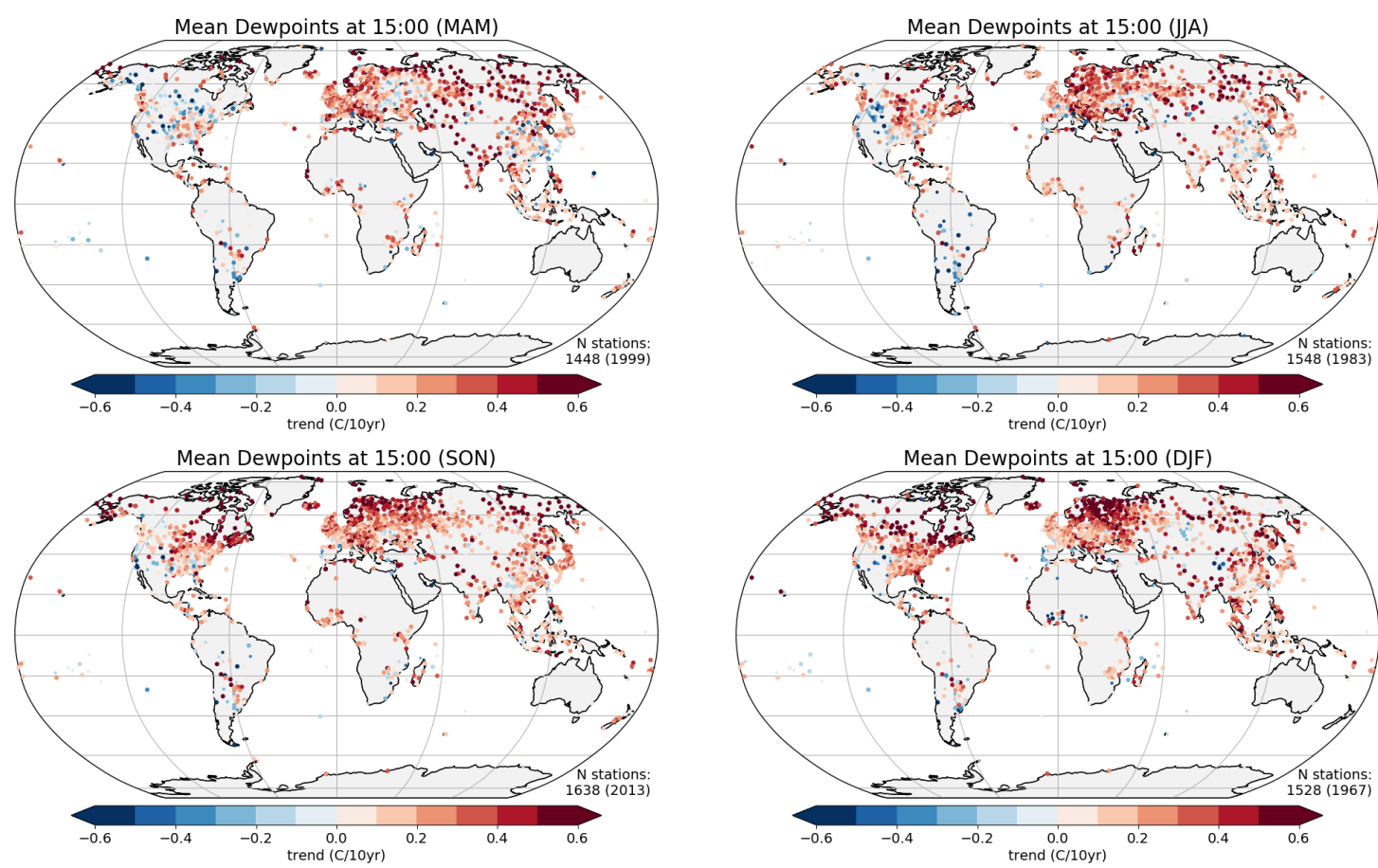

Figure S21. Trend over 1974-2018 in distribution mean for dewpoint temperature at 1500 local time across the four seasons. The stations where the $1 \hat{\sigma}$ range of the fitted trend excludes zero are plotted with a larger symbol (the number of these is shown in the bottom right hand corner of each plot). The total number of stations available is shown in parentheses.
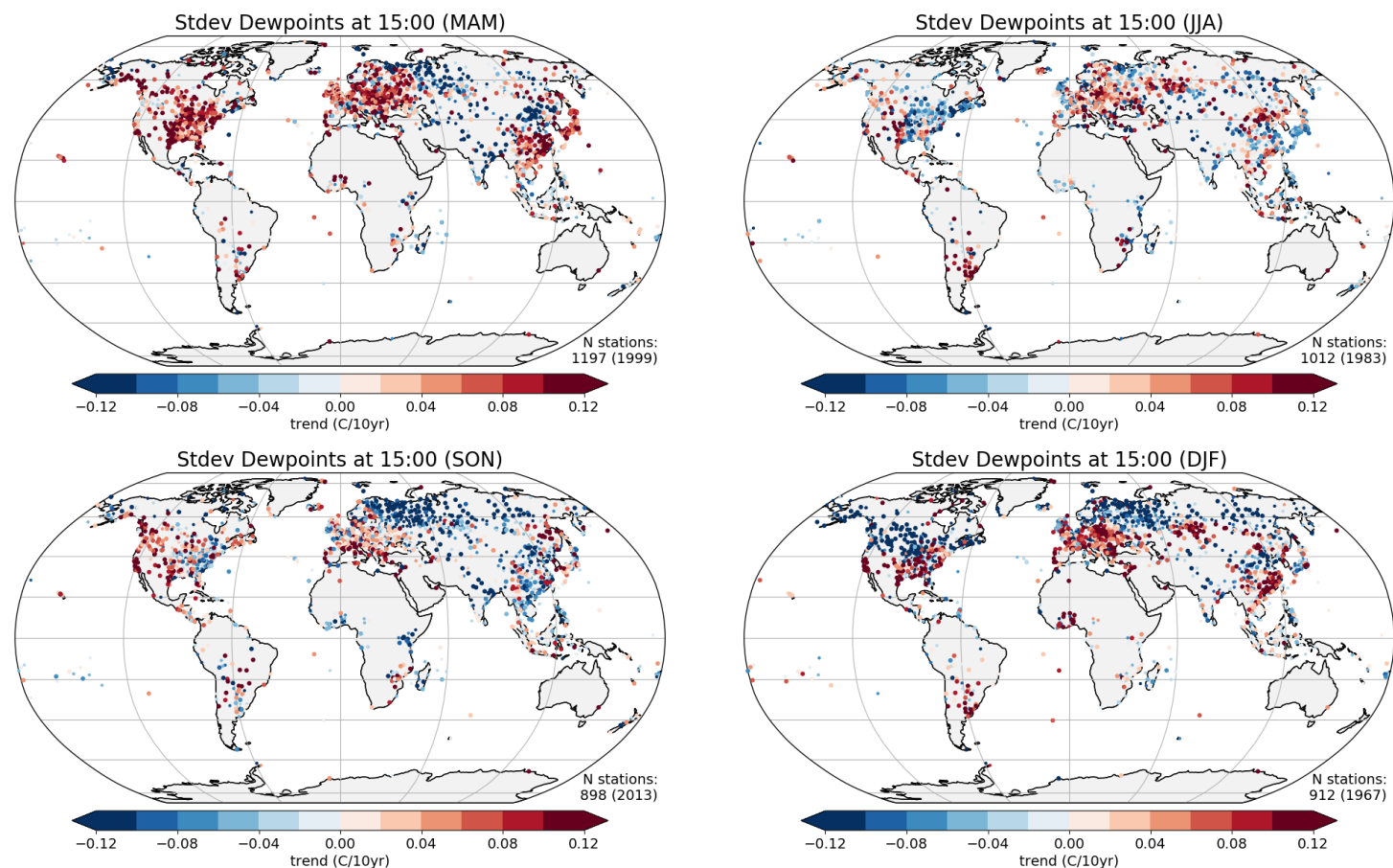

Figure S22. Trend over 1974-2018 in distribution standard deviation for dewpoint temperature at 1500 local time across the four seasons. The stations where the $1 \hat{\sigma}$ range of the fitted trend excludes zero are plotted with a larger symbol (the number of these is shown in the bottom right hand corner of each plot). The total number of stations available is shown in parentheses. 

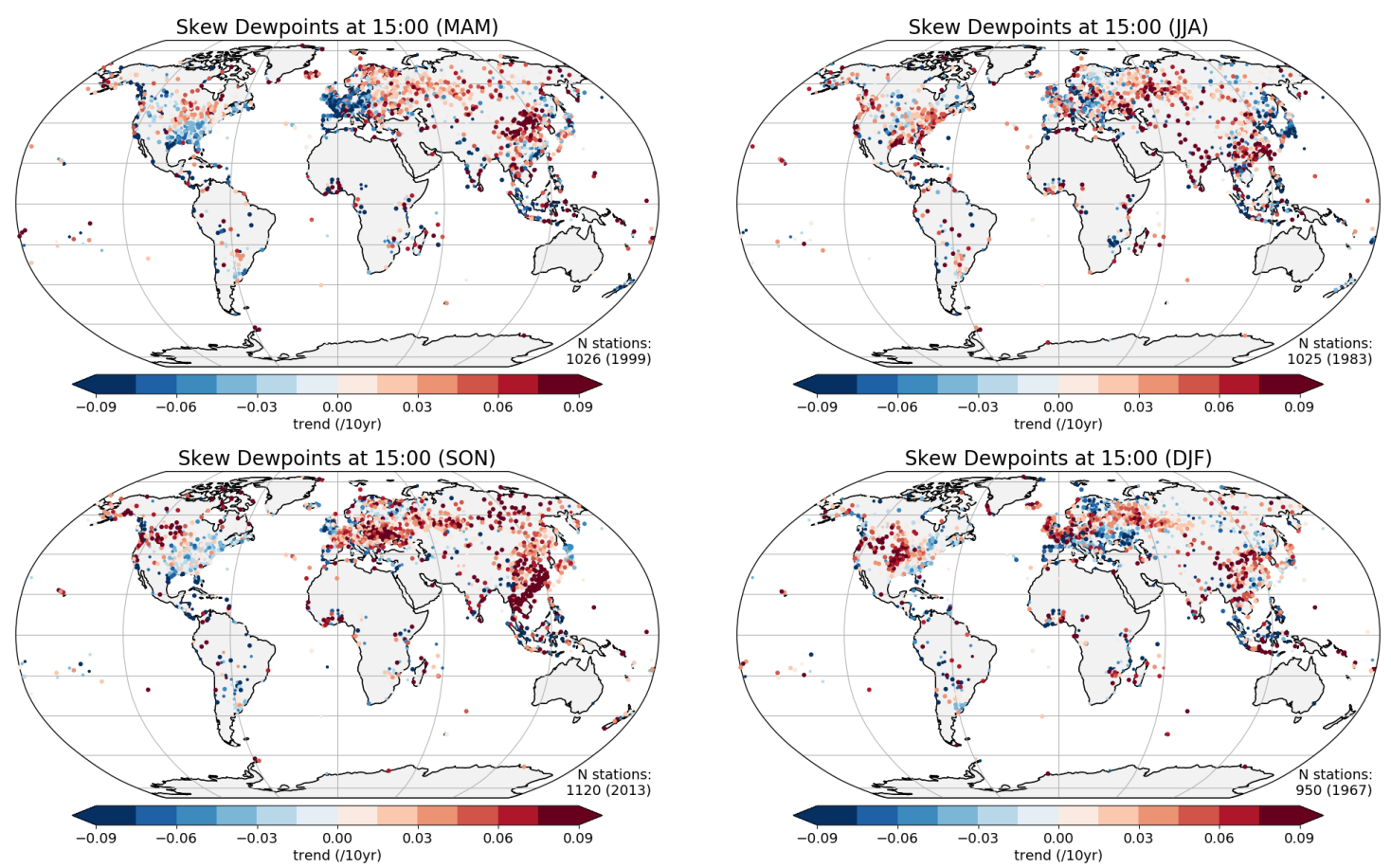

Figure S23. Trend over 1974-2018 in distribution skew for dewpoint temperature at 1500 local time across the four seasons. The stations where the $1 \hat{\sigma}$ range of the fitted trend excludes zero are plotted with a larger symbol (the number of these is shown in the bottom right hand corner of each plot). The total number of stations available is shown in parentheses.
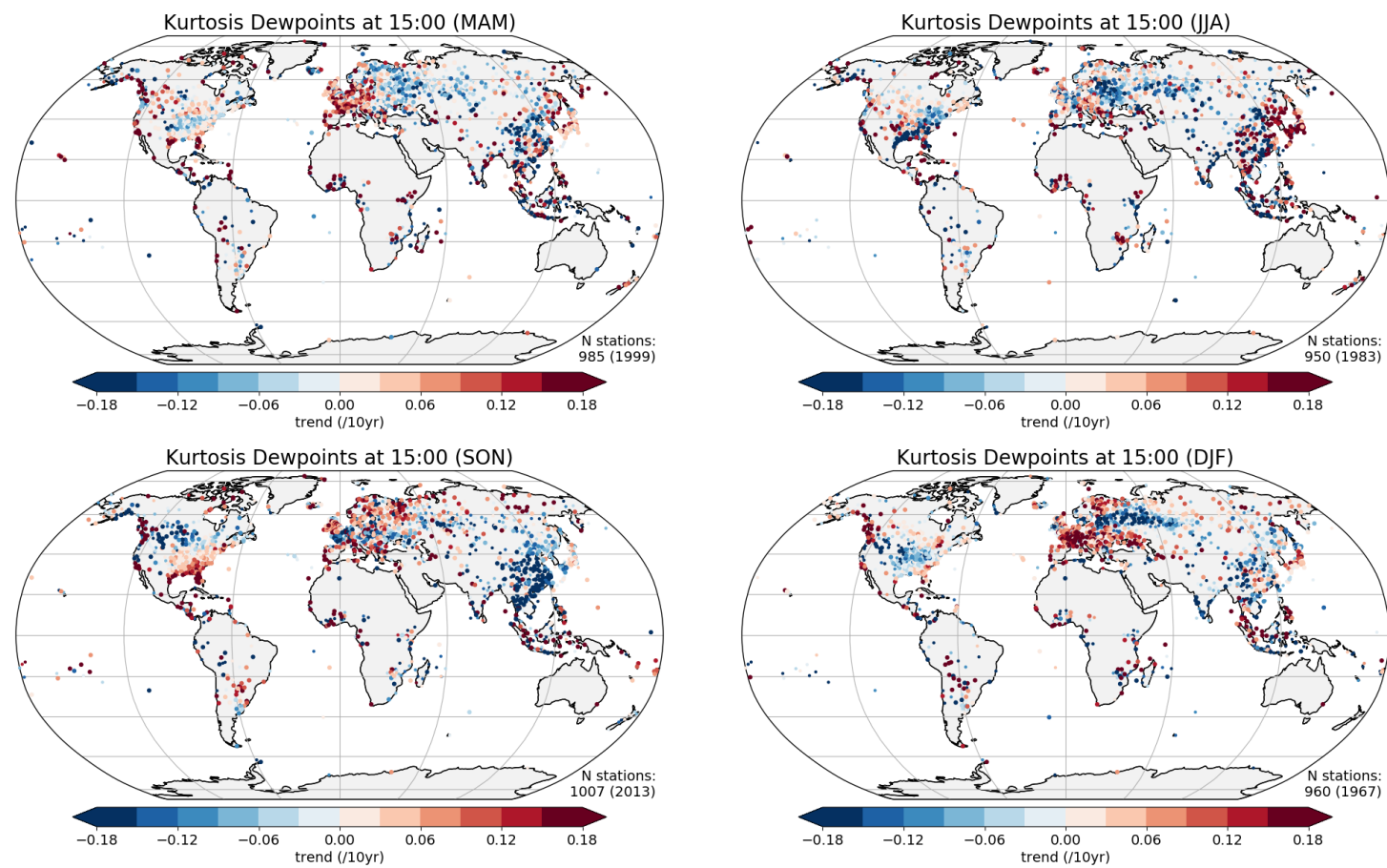

Figure S24. Trend over 1974-2018 in distribution kurtosis for dewpoint temperature at 1500 local time across the four seasons. The stations where the $1 \hat{\sigma}$ range of the fitted trend excludes zero are plotted with a larger symbol (the number of these is shown in the bottom right hand corner of each plot). The total number of stations available is shown in parentheses. 

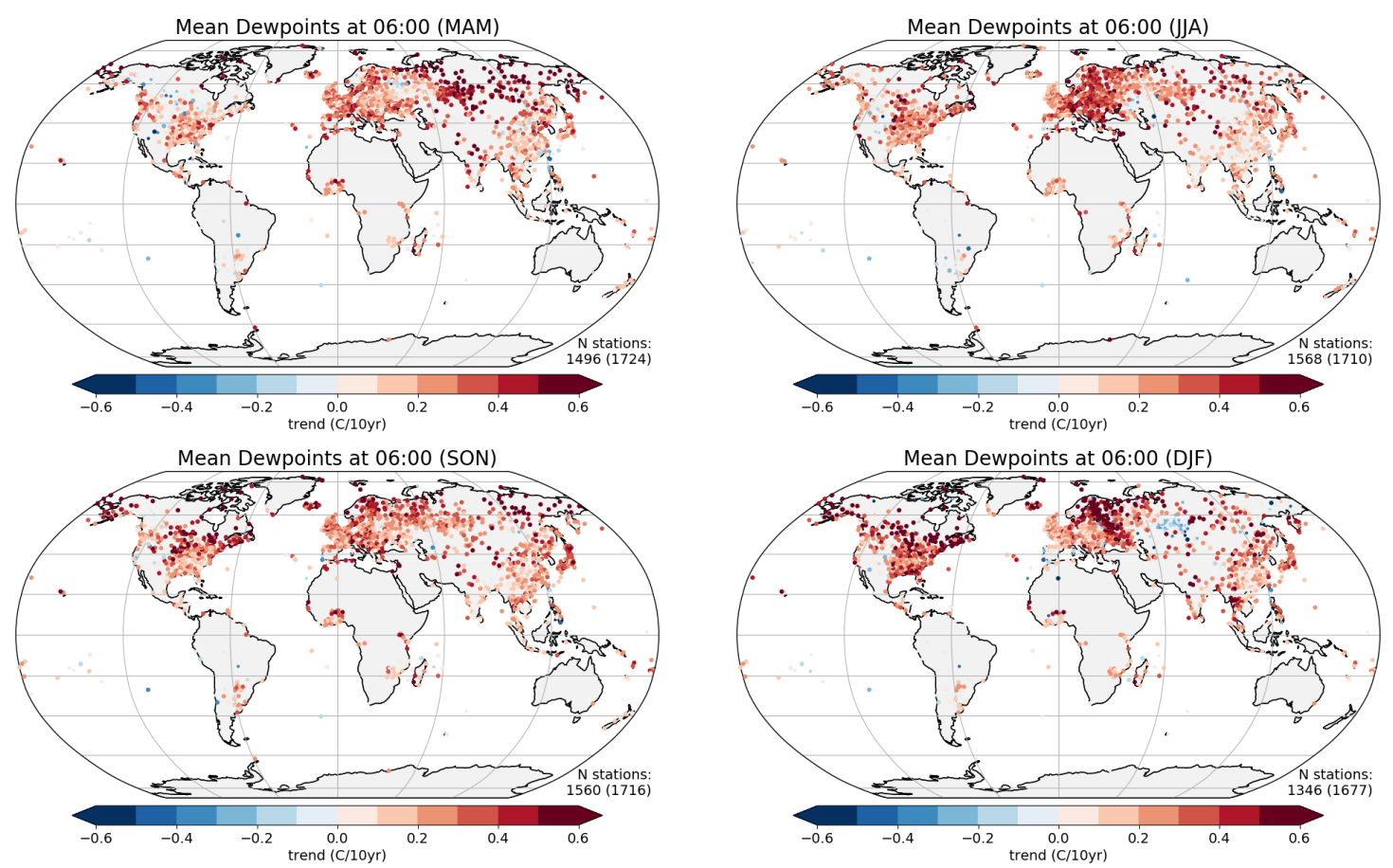

Figure S25. Trend over 1974-2018 in distribution mean for dewpoint temperature at 0600 local time across the four seasons. The stations where the $1 \hat{\sigma}$ range of the fitted trend excludes zero are plotted with a larger symbol (the number of these is shown in the bottom right hand corner of each plot). The total number of stations available is shown in parentheses.
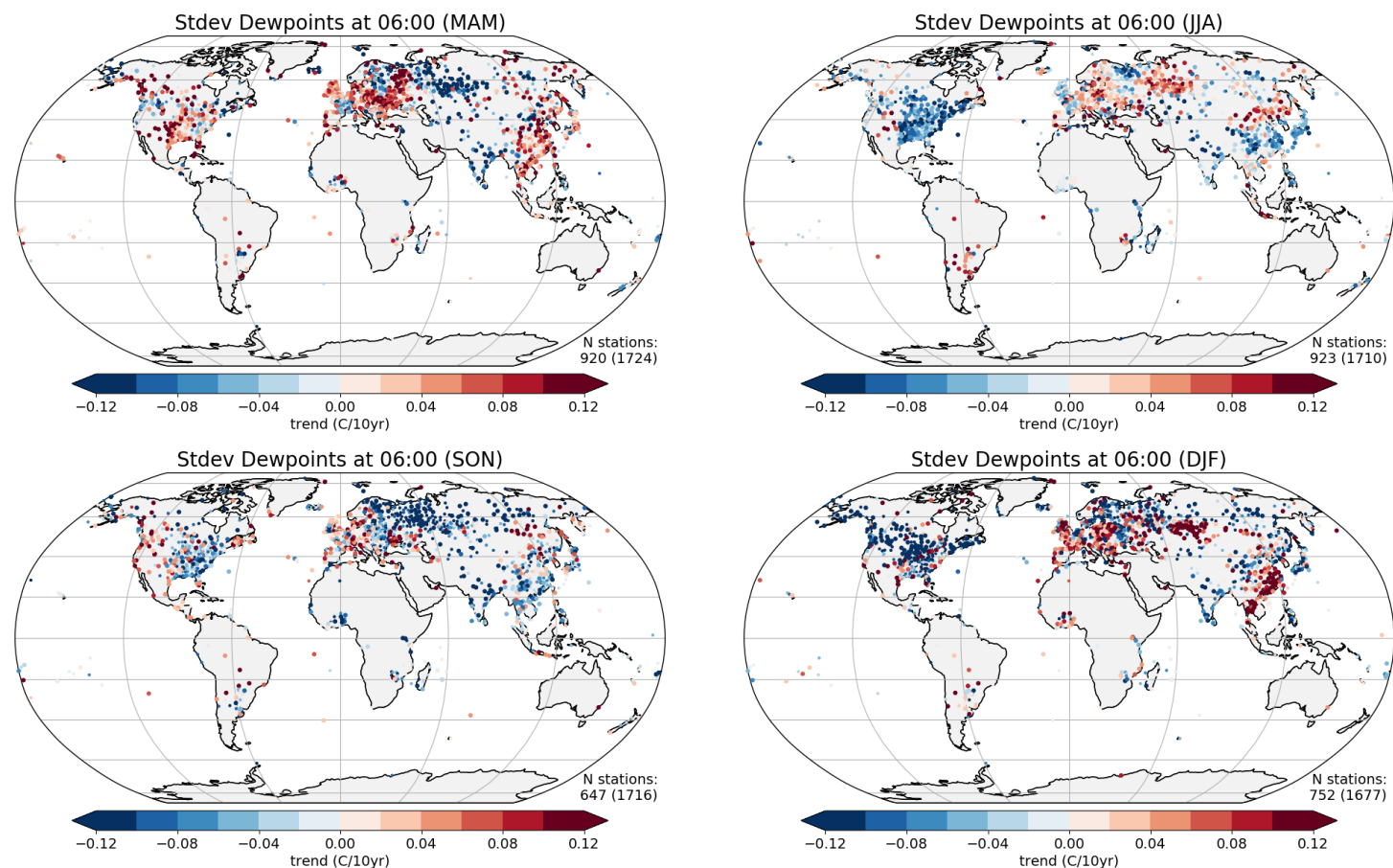

Figure S26. Trend over 1974-2018 in distribution standard deviation for dewpoint temperature at 0600 local time across the four seasons. The stations where the $1 \hat{\sigma}$ range of the fitted trend excludes zero are plotted with a larger symbol (the number of these is shown in the bottom right hand corner of each plot). The total number of stations available is shown in parentheses. 

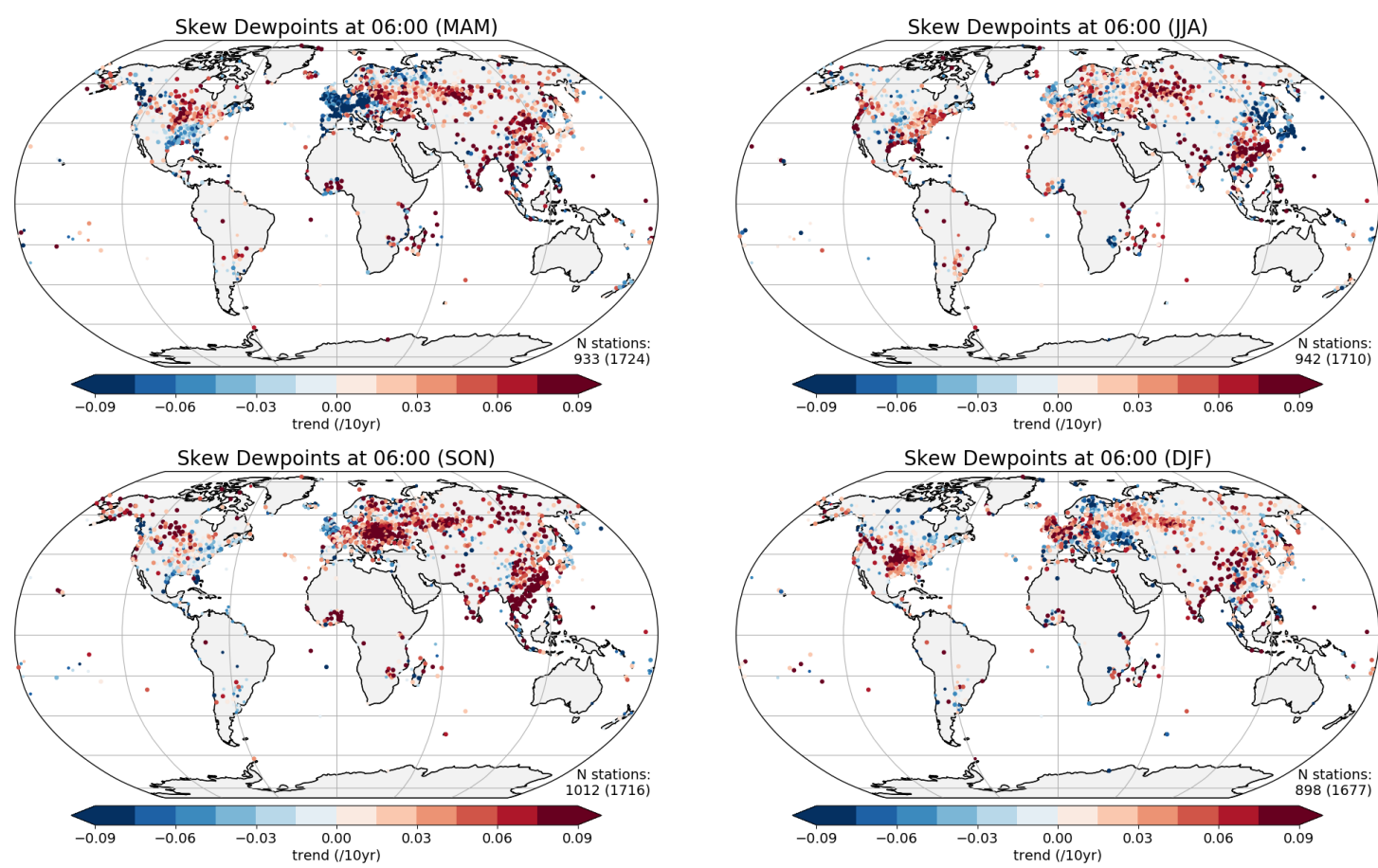

Figure S27. Trend over 1974-2018 in distribution skew for dewpoint temperature at 0600 local time across the four seasons. The stations where the $1 \hat{\sigma}$ range of the fitted trend excludes zero are plotted with a larger symbol (the number of these is shown in the bottom right hand corner of each plot). The total number of stations available is shown in parentheses.
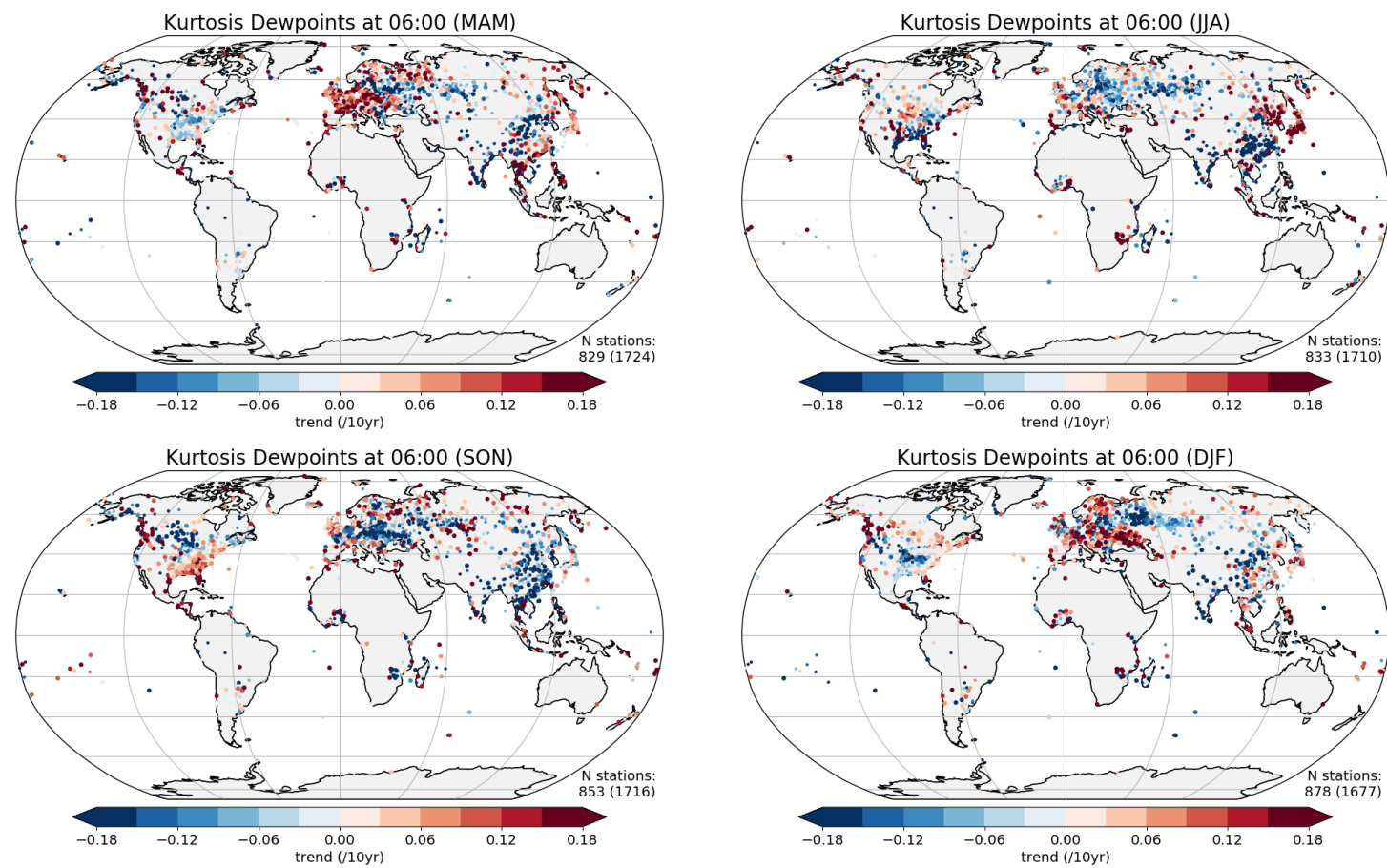

Figure S28. Trend over 1974-2018 in distribution kurtosis for dewpoint temperature at 0600 local time across the four seasons. The stations where the $1 \hat{\sigma}$ range of the fitted trend excludes zero are plotted with a larger symbol (the number of these is shown in the bottom right hand corner of each plot). The total number of stations available is shown in parentheses. 

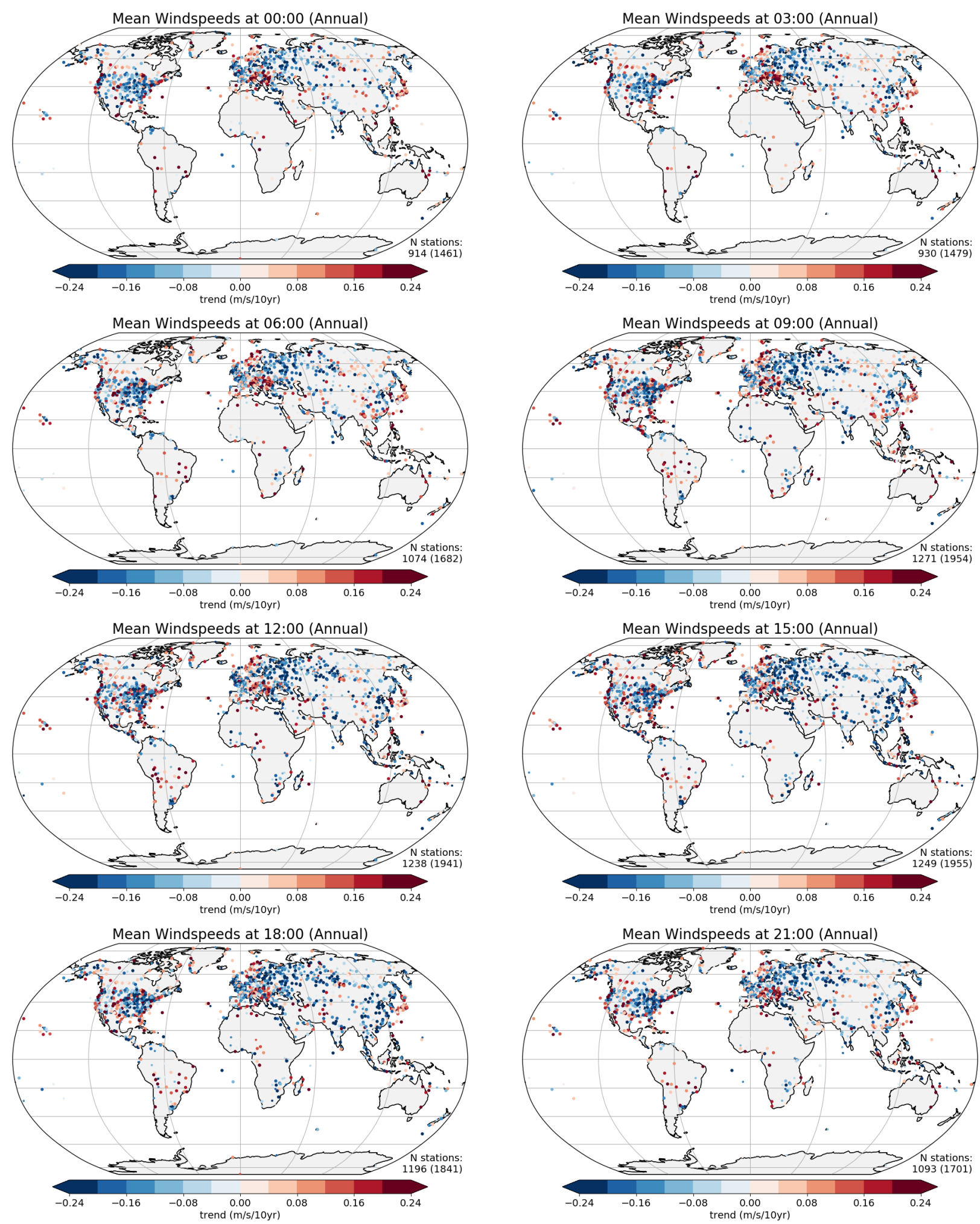

Figure S29. Trend over 1974-2018 in distribution mean for wind speeds at each three hourly interval. The stations where the $1 \hat{\sigma}$ range of the fitted trend excludes zero are plotted with a larger symbol (the number of these is shown in the bottom right hand corner of each plot). The total number of stations available is shown in parentheses. 

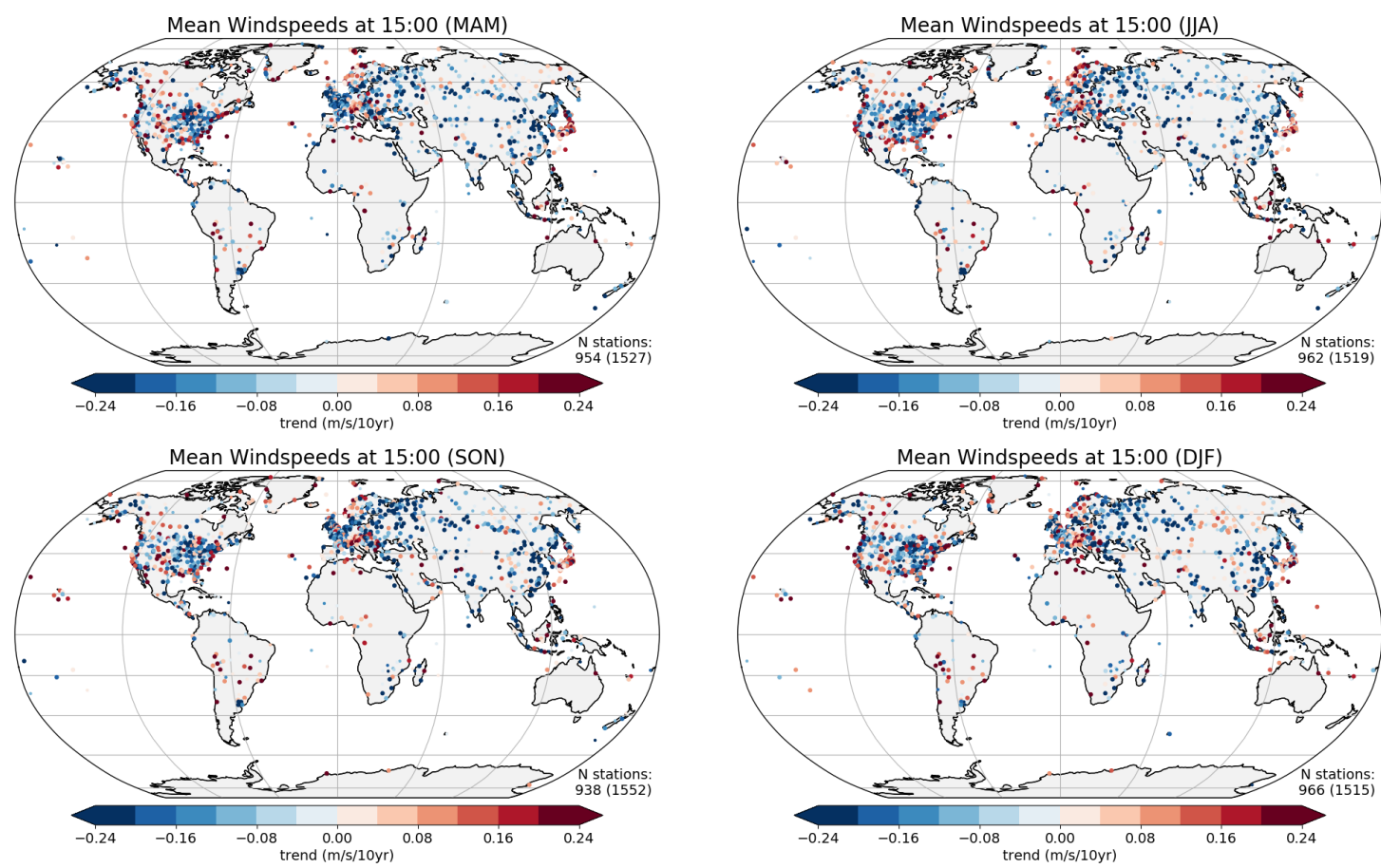

Figure S30. Trend over 1974-2018 in distribution mean for wind speeds at 1500 local time across the four seasons. The stations where the $1 \hat{\sigma}$ range of the fitted trend excludes zero are plotted with a larger symbol (the number of these is shown in the bottom right hand corner of each plot). The total number of stations available is shown in parentheses.
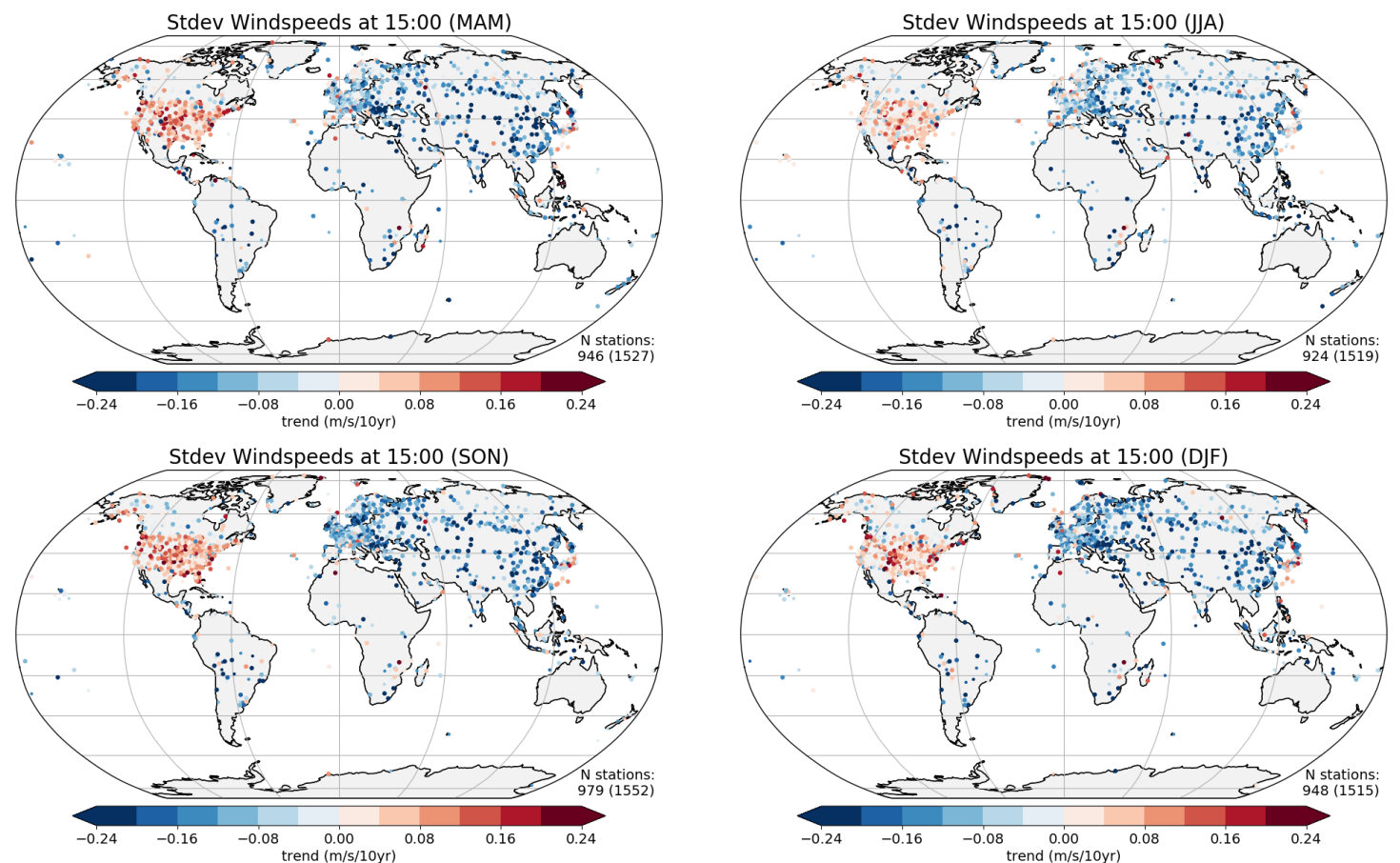

Figure S31. Trend over 1974-2018 in distribution standard deviation for wind speeds at 1500 local time across the four seasons. The stations where the $1 \hat{\sigma}$ range of the fitted trend excludes zero are plotted with a larger symbol (the number of these is shown in the bottom right hand corner of each plot). The total number of stations available is shown in parentheses. 

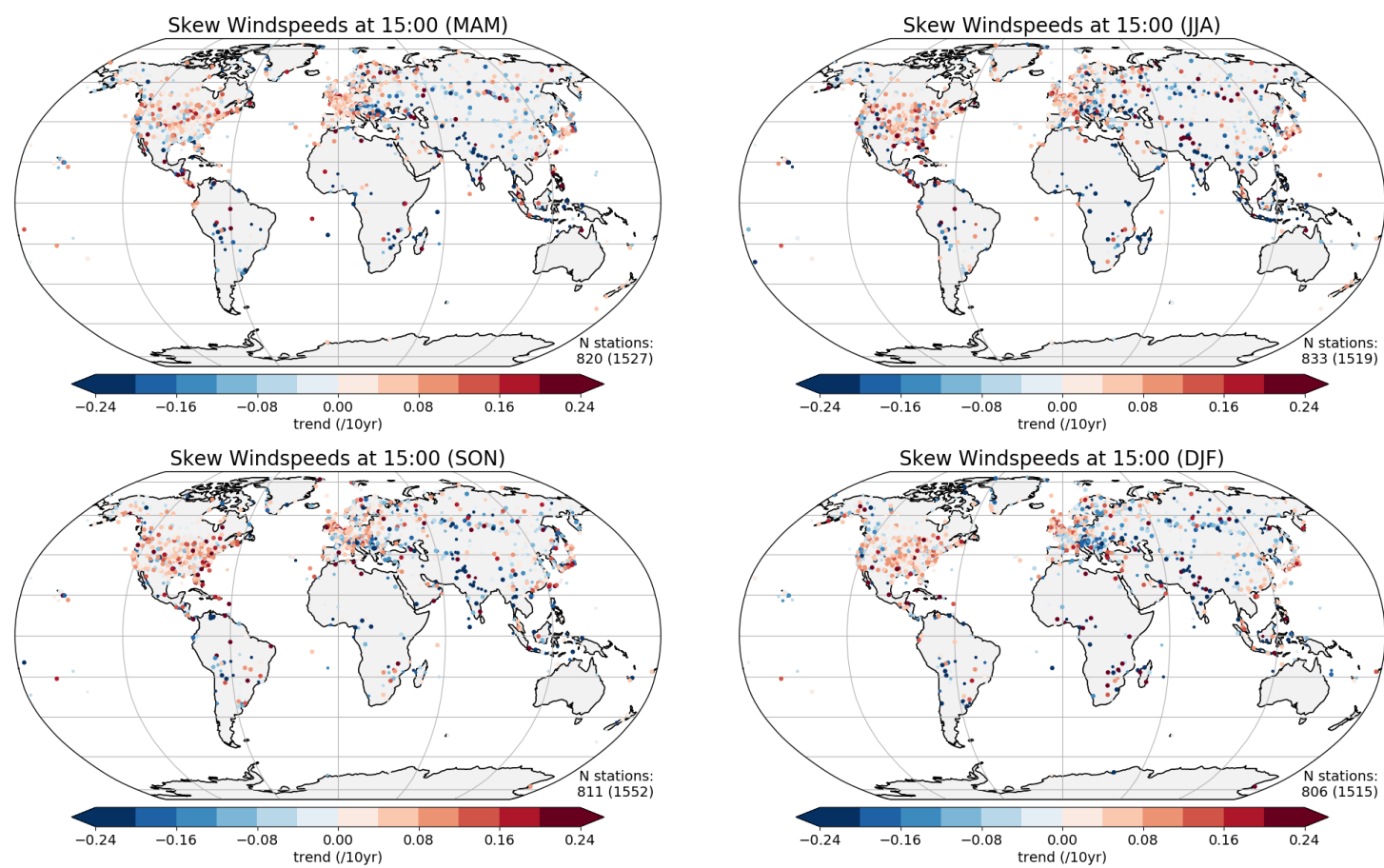

Figure S32. Trend over 1974-2018 in distribution skew for wind speeds at 1500 local time across the four seasons. The stations where the $1 \hat{\sigma}$ range of the fitted trend excludes zero are plotted with a larger symbol (the number of these is shown in the bottom right hand corner of each plot). The total number of stations available is shown in parentheses.
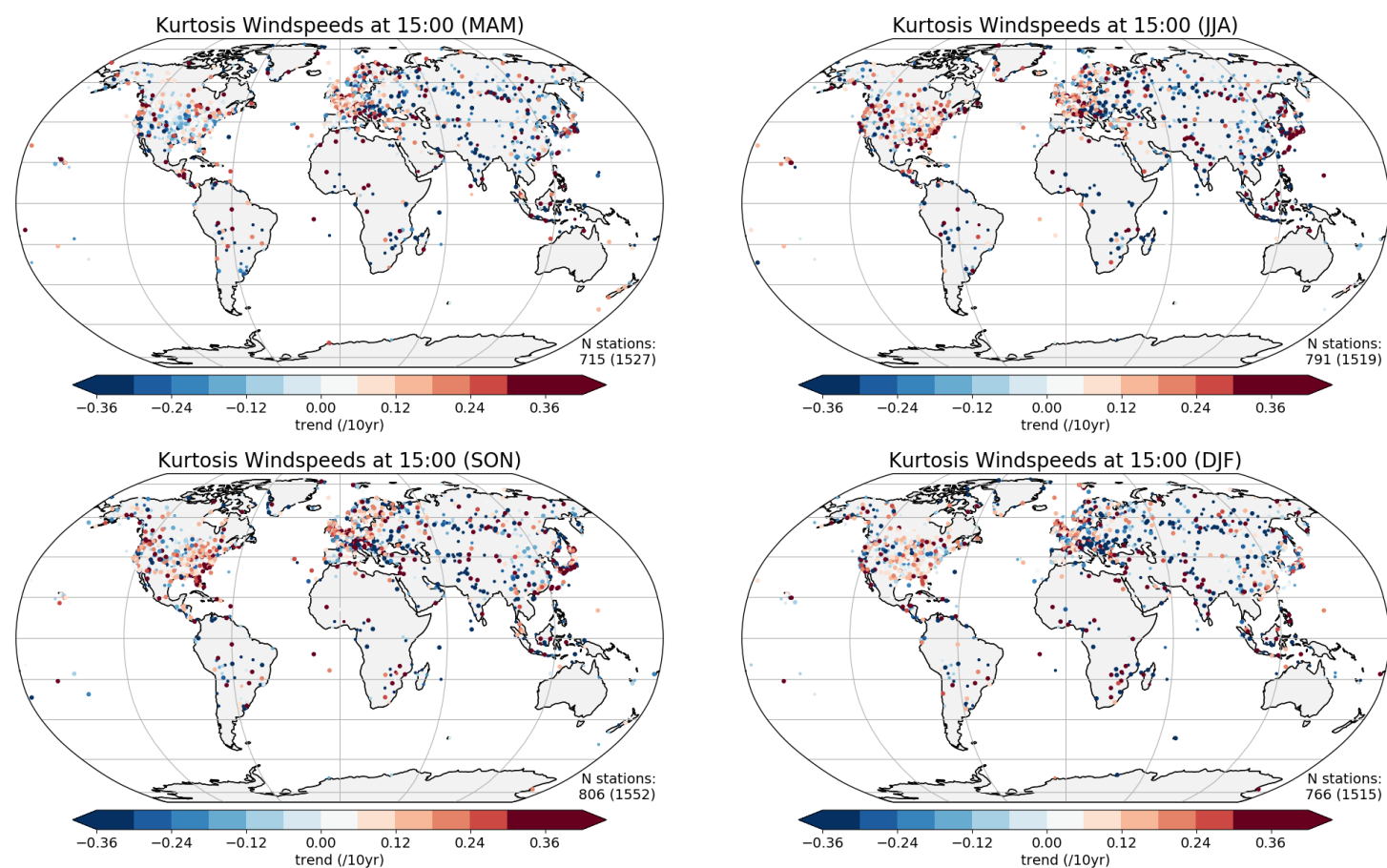

Figure S33. Trend over 1974-2018 in distribution kurtosis for wind speeds at 1500 local time across the four seasons. The stations where the $1 \hat{\sigma}$ range of the fitted trend excludes zero are plotted with a larger symbol (the number of these is shown in the bottom right hand corner of each plot). The total number of stations available is shown in parentheses. 

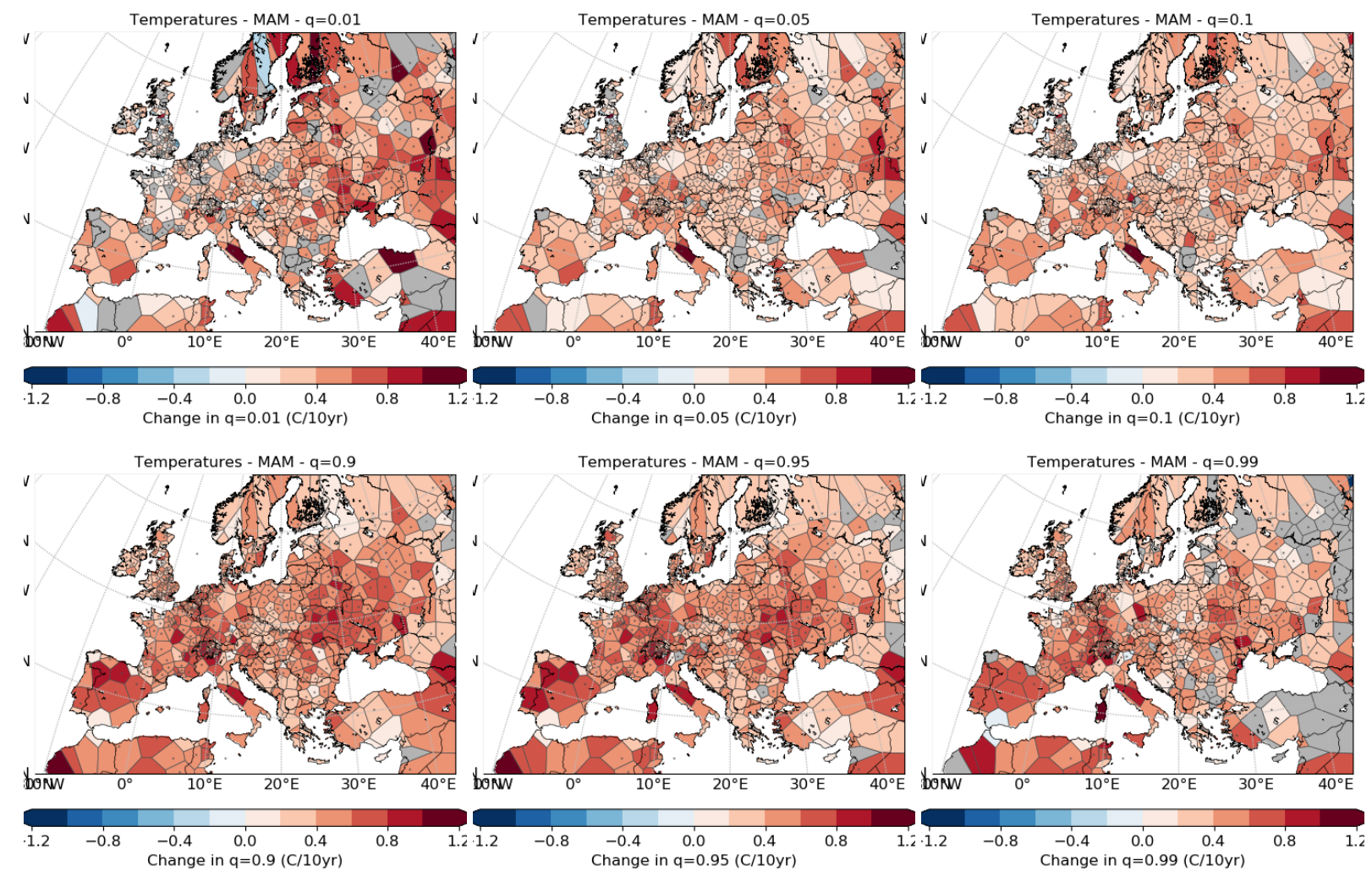

Figure S34. Trend over 1973-2017 in quantiles of temperature $\left({ }^{\circ} \mathrm{C}\right.$ decade $\left.^{-1}\right)$ at TOP 0.01, 0.05 and 0.10; and вОтТОм 0.90, 0.95, 0.99 over Europe (MAM). 

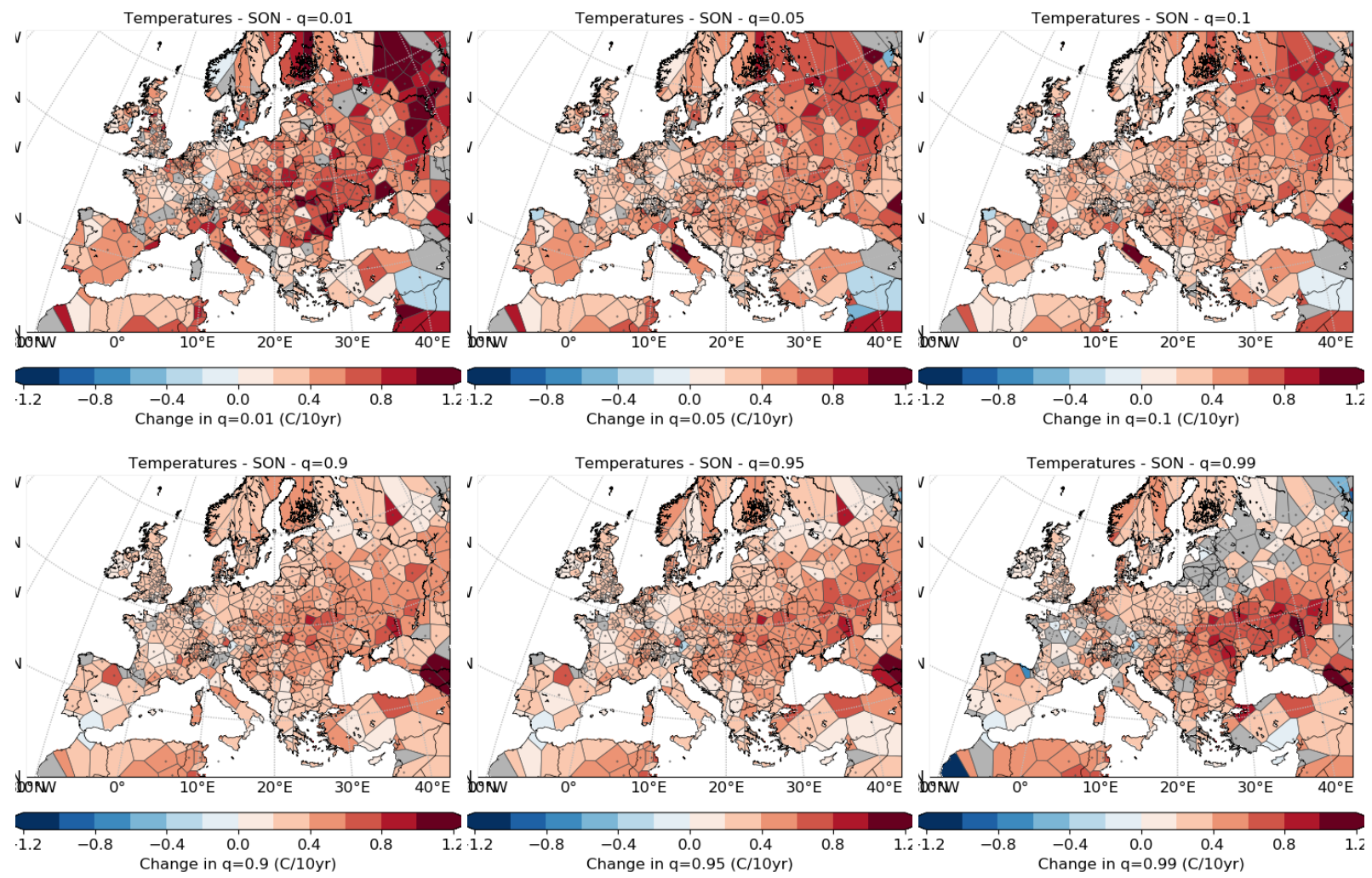

Figure S35. Trend over 1973-2017 in quantiles of temperature $\left({ }^{\circ} \mathrm{C}\right.$ decade $\left.{ }^{-1}\right)$ at TOP $0.01,0.05$ and 0.10 ; and BOTTOM $0.90,0.95,0.99$ over Europe (SON). 

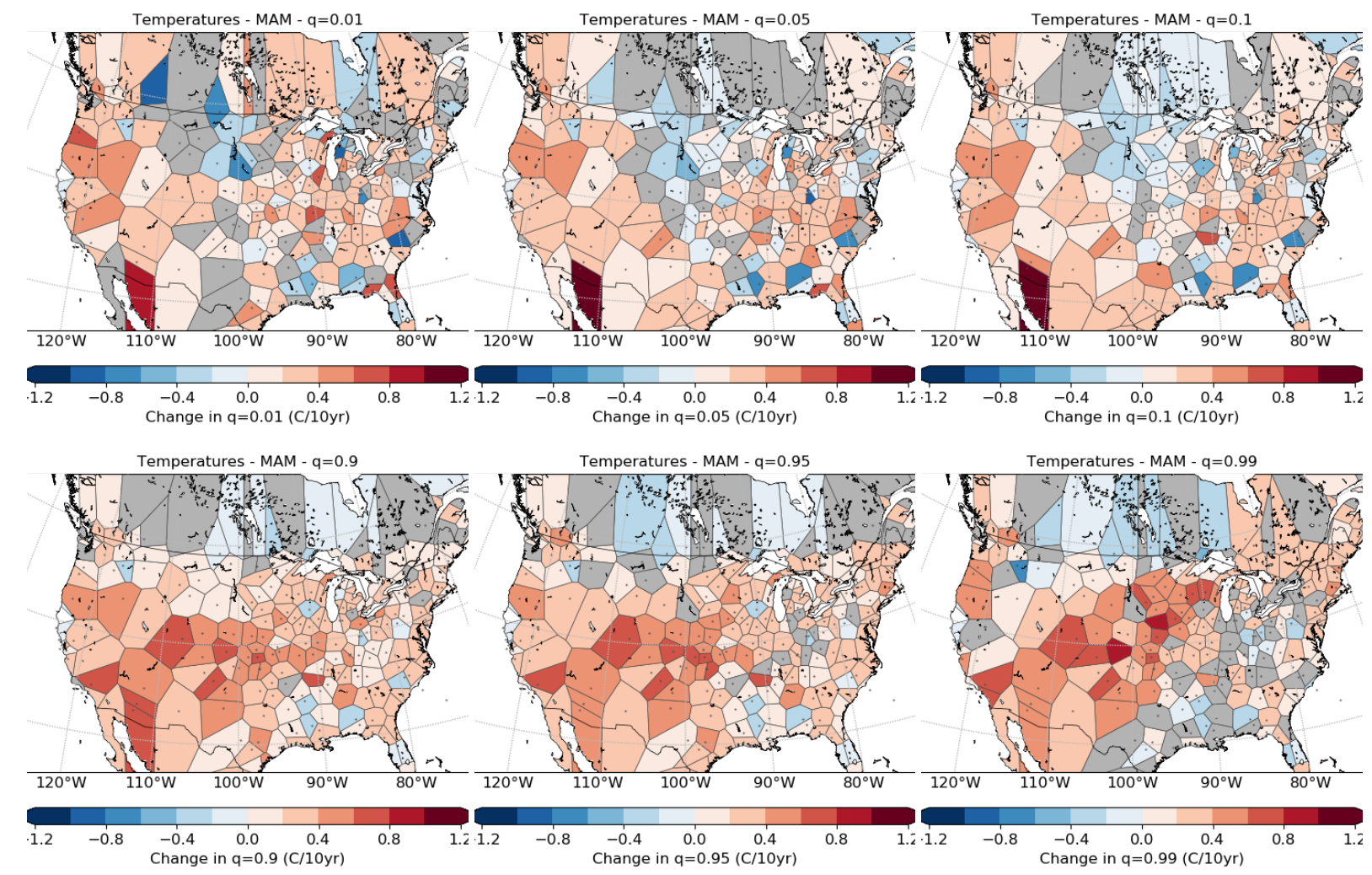

Figure S36. Trend over 1973-2017 in quantiles of temperature $\left({ }^{\circ} \mathrm{C}\right.$ decade $\left.^{-1}\right)$ at тоР $0.01,0.05$ and 0.10; and воттом 0.90, 0.95, 0.99 over North America (MAM). 

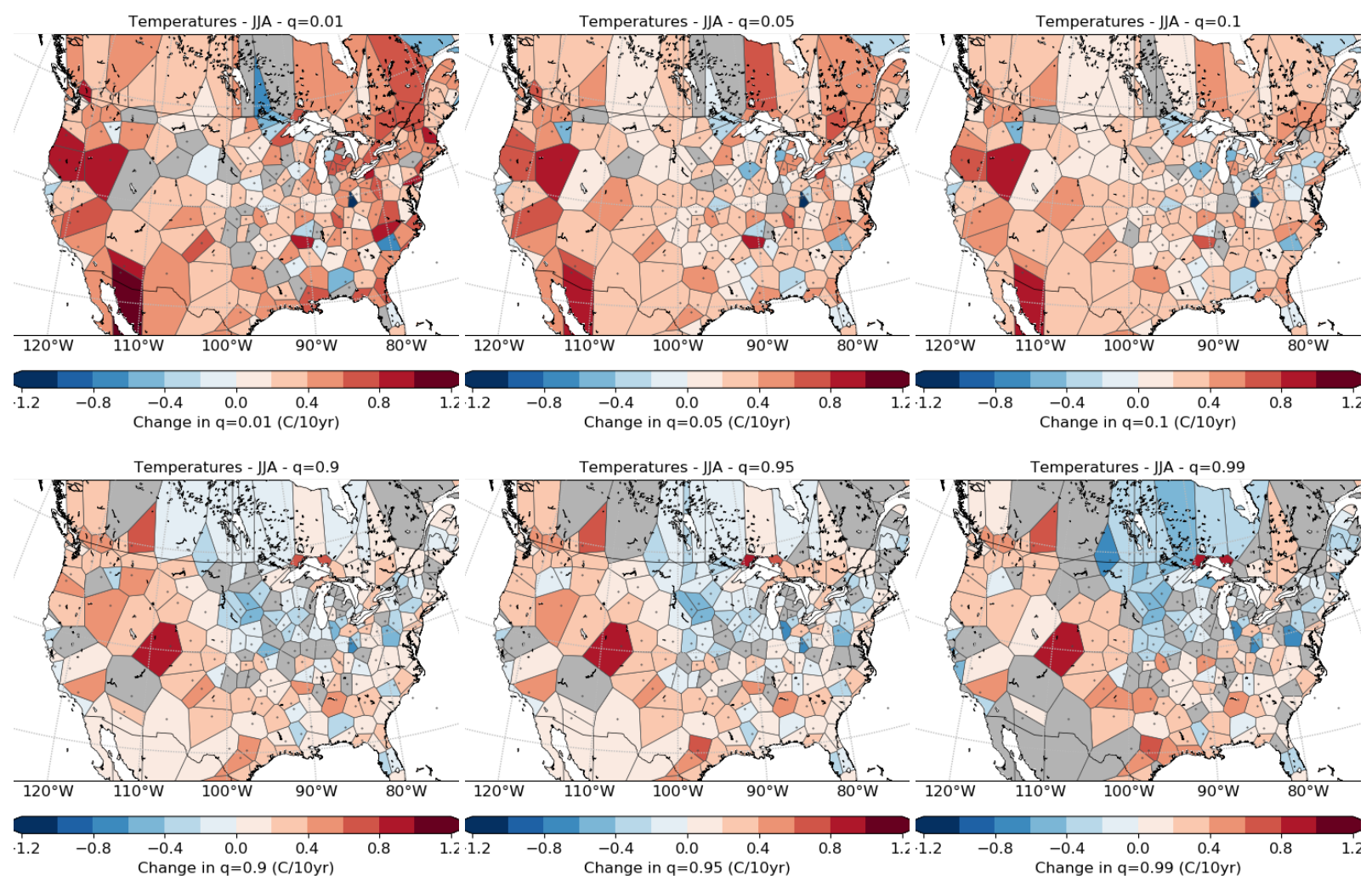

Figure S37. Trend over 1973-2017 in quantiles of temperature $\left({ }^{\circ} \mathrm{C}\right.$ decade $\left.{ }^{-1}\right)$ at TOP $0.01,0.05$ and $0.10 ;$ and BOTTOM $0.90,0.95,0.99$ over North America (JJA). 

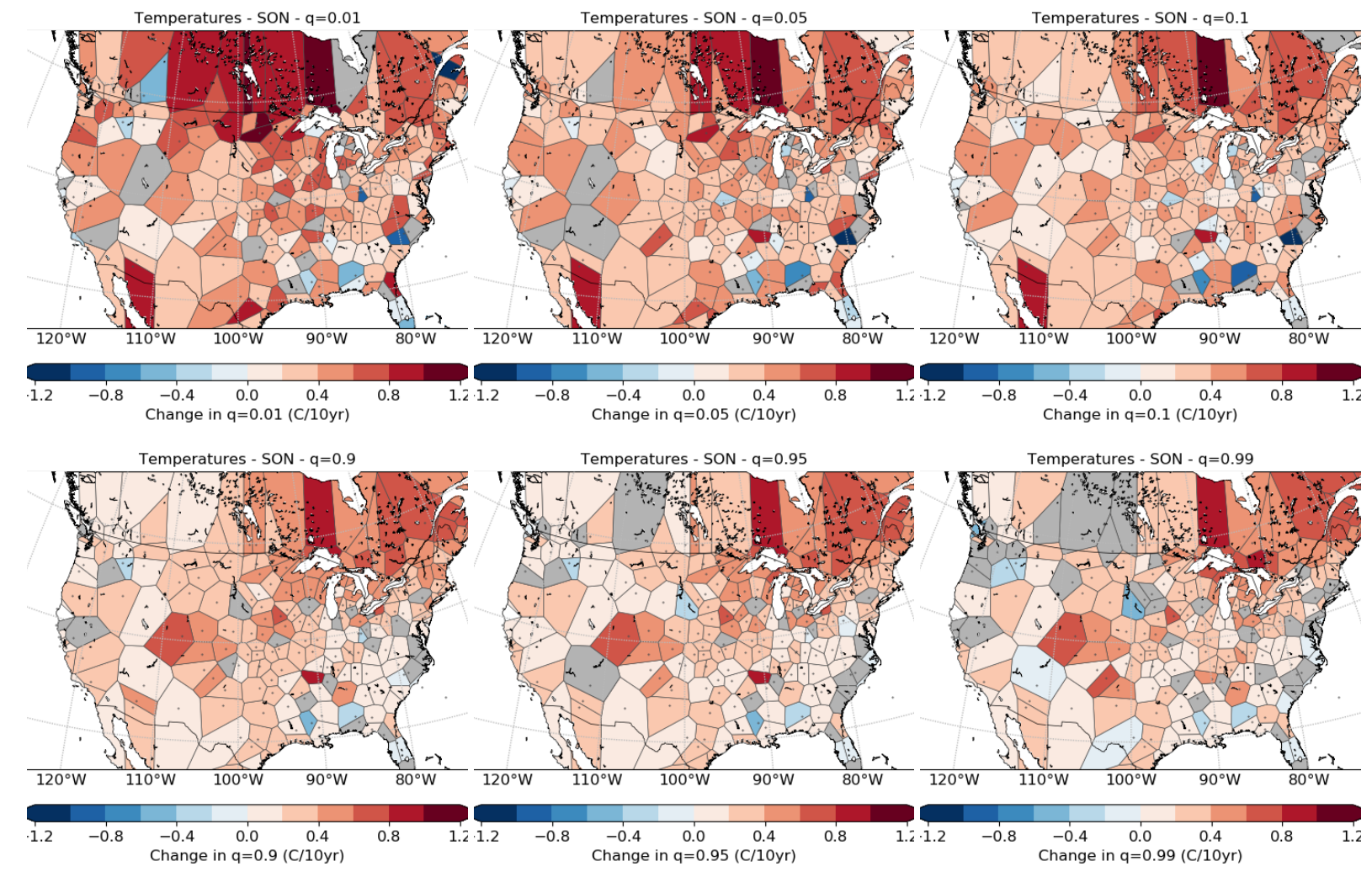

Figure S38. Trend over 1973-2017 in quantiles of temperature $\left({ }^{\circ} \mathrm{C}\right.$ decade $\left.^{-1}\right)$ at тоР $0.01,0.05$ and 0.10 ; and воттом 0.90, 0.95, 0.99 over North America (SON). 

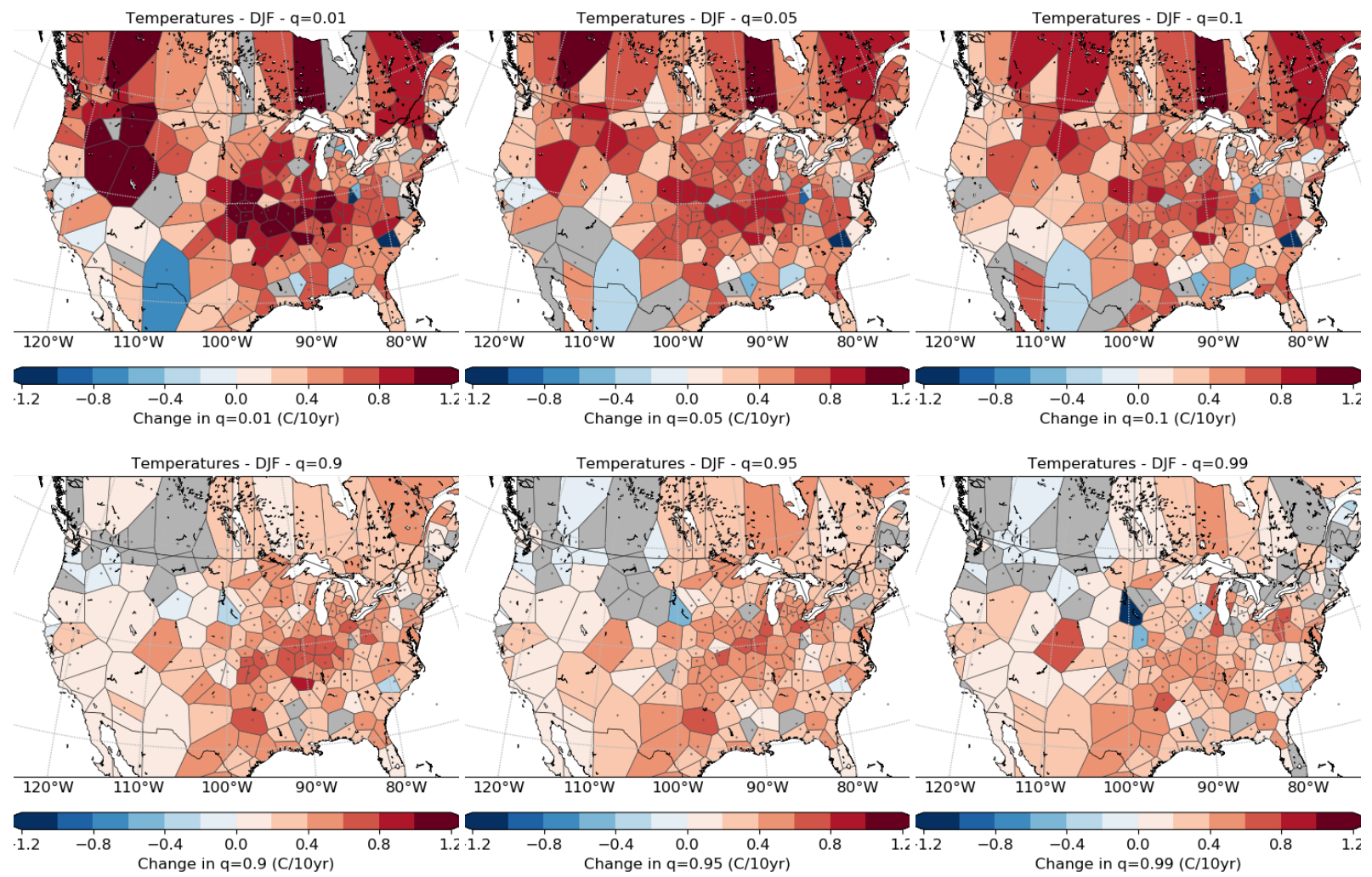

Figure S39. Trend over 1973-2017 in quantiles of temperature $\left({ }^{\circ} \mathrm{C}\right.$ decade $\left.{ }^{-1}\right)$ at TOP $0.01,0.05$ and $0.10 ;$ and BOTTOM $0.90,0.95,0.99$ over North America (DJF. 

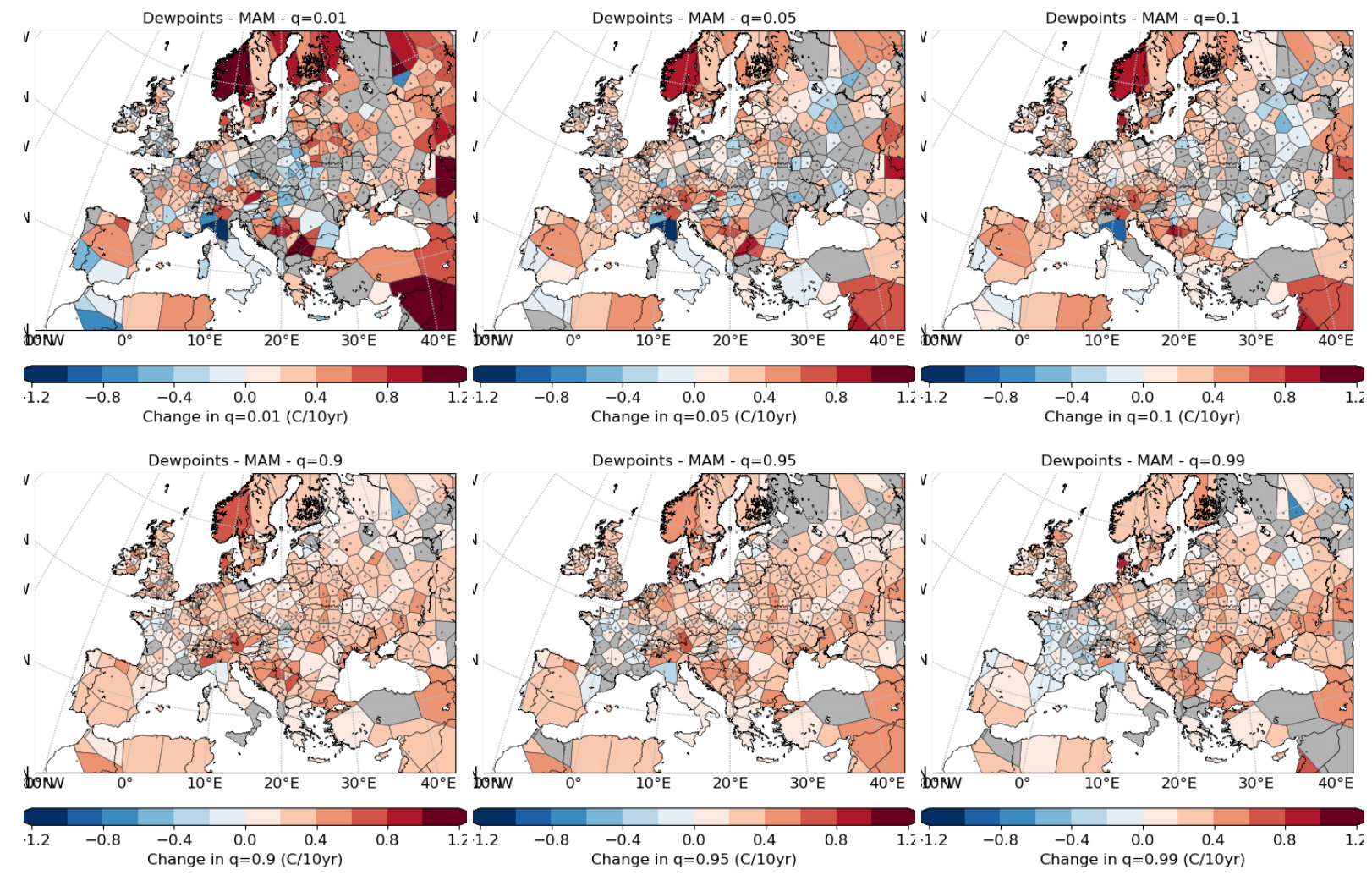

Figure S40. Trend over 1973-2017 in quantiles of dewpoint temperature $\left({ }^{\circ} \mathrm{C}\right.$ decade $\left.{ }^{-1}\right)$ at TOP 0.01, 0.05 and 0.10; and BOTтом 0.90, 0.95, 0.99 over Europe (MAM). 

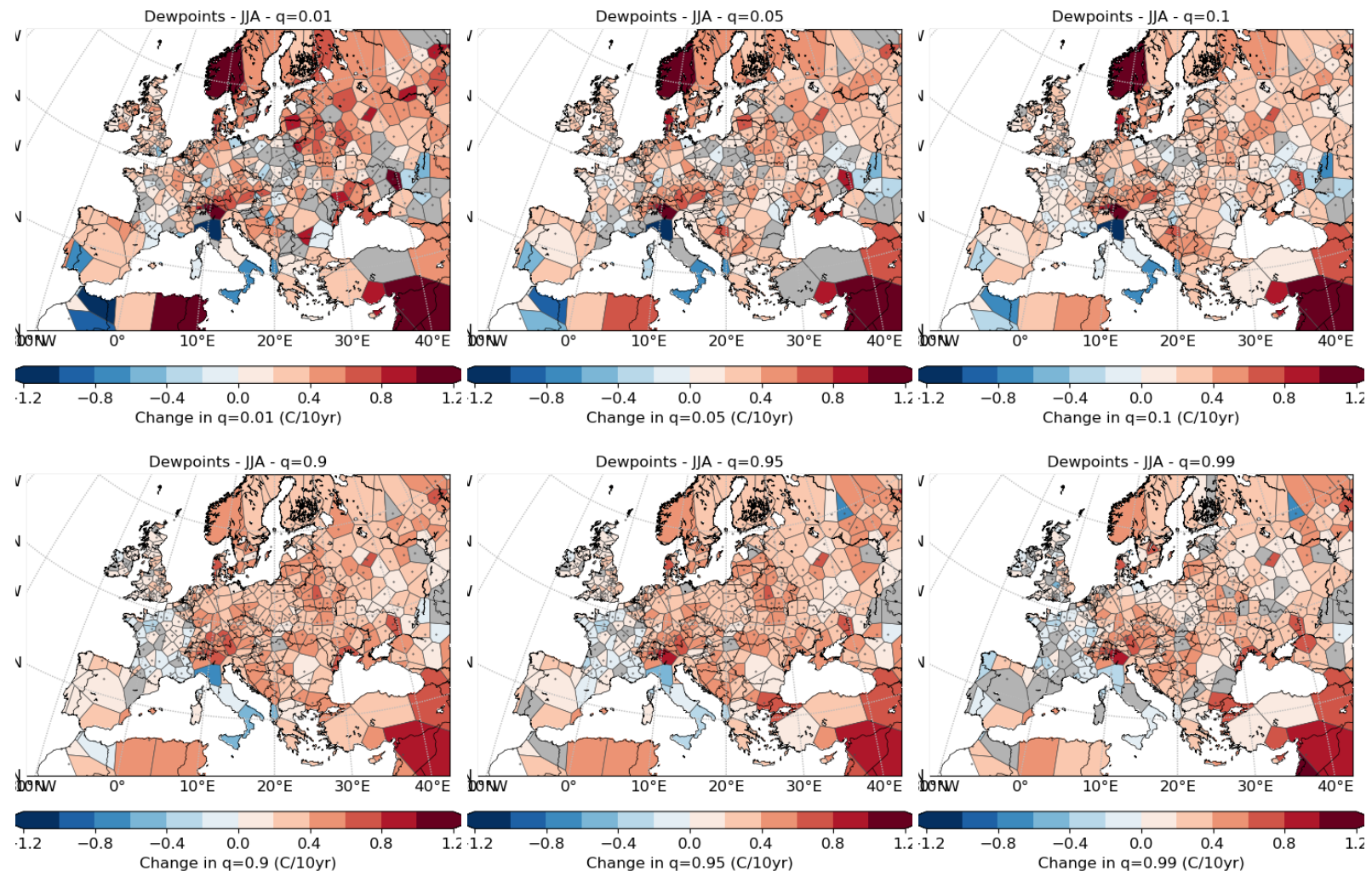

Figure S41. Trend over 1973-2017 in quantiles of dewpoint temperature $\left({ }^{\circ} \mathrm{C}\right.$ decade $\left.{ }^{-1}\right)$ at TOP $0.01,0.05$ and 0.10 ; and BOTTOM $0.90,0.95$, 0.99 over Europe (JJA). 

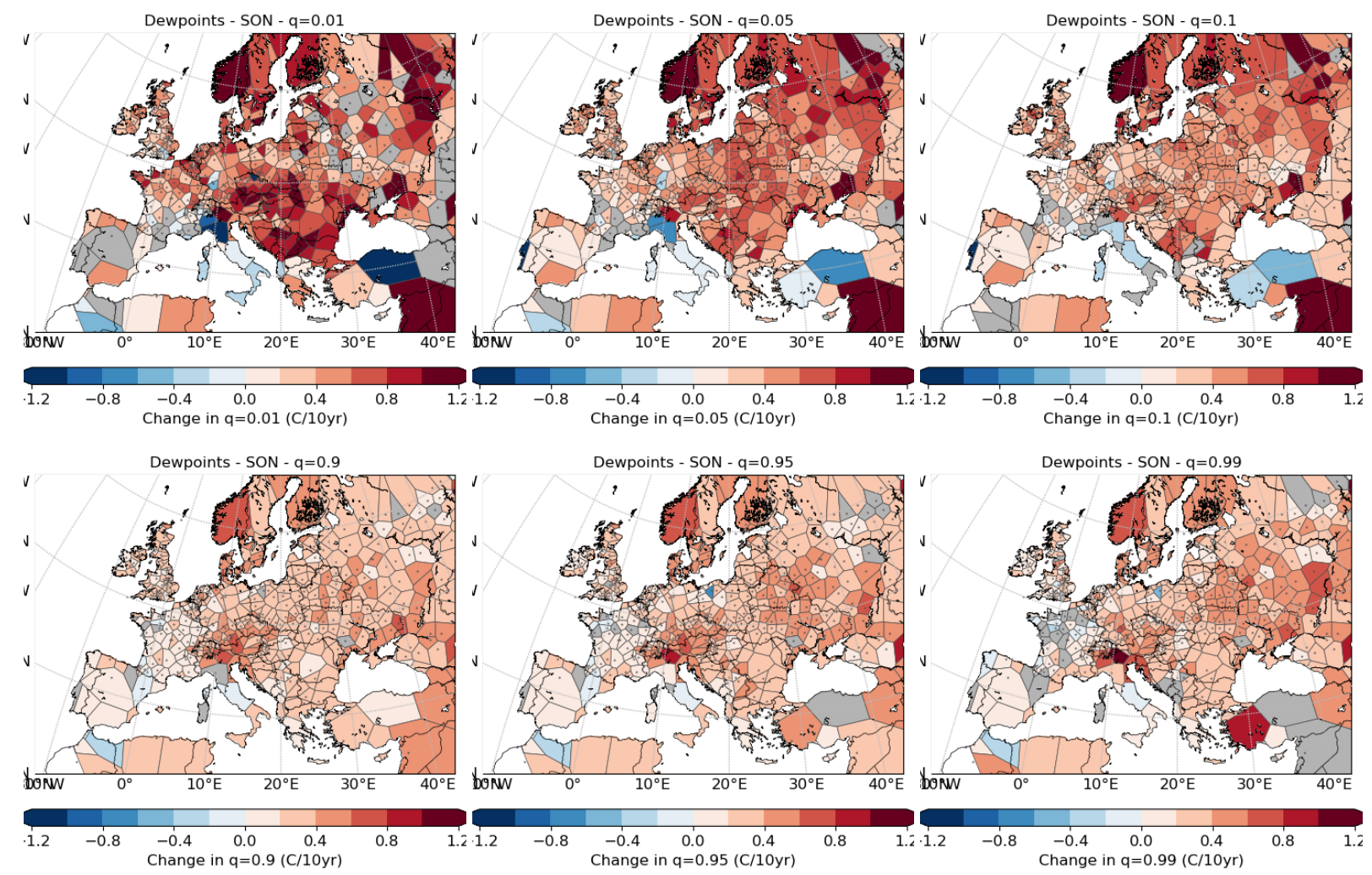

Figure S42. Trend over 1973-2017 in quantiles of dewpoint temperature $\left({ }^{\circ} \mathrm{C}\right.$ decade $\left.{ }^{-1}\right)$ at TOP 0.01, 0.05 and 0.10; and BOTтом 0.90, 0.95, 0.99 over Europe (SON). 

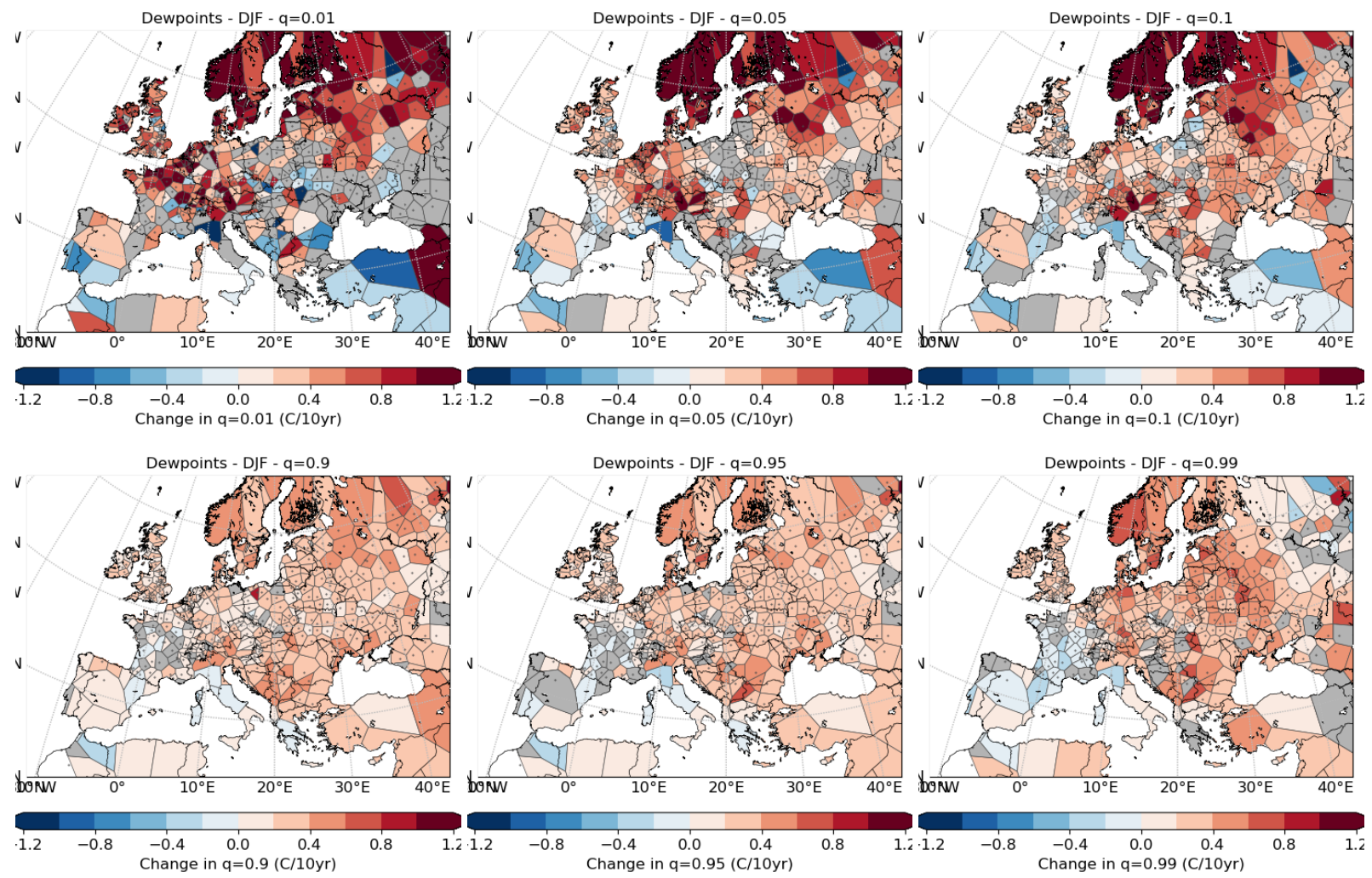

Figure S43. Trend over 1973-2017 in quantiles of dewpoint temperature $\left({ }^{\circ} \mathrm{C}\right.$ decade $\left.{ }^{-1}\right)$ at TOP $0.01,0.05$ and 0.10 ; and BOTTOM $0.90,0.95$, 0.99 over Europe (DJF). 

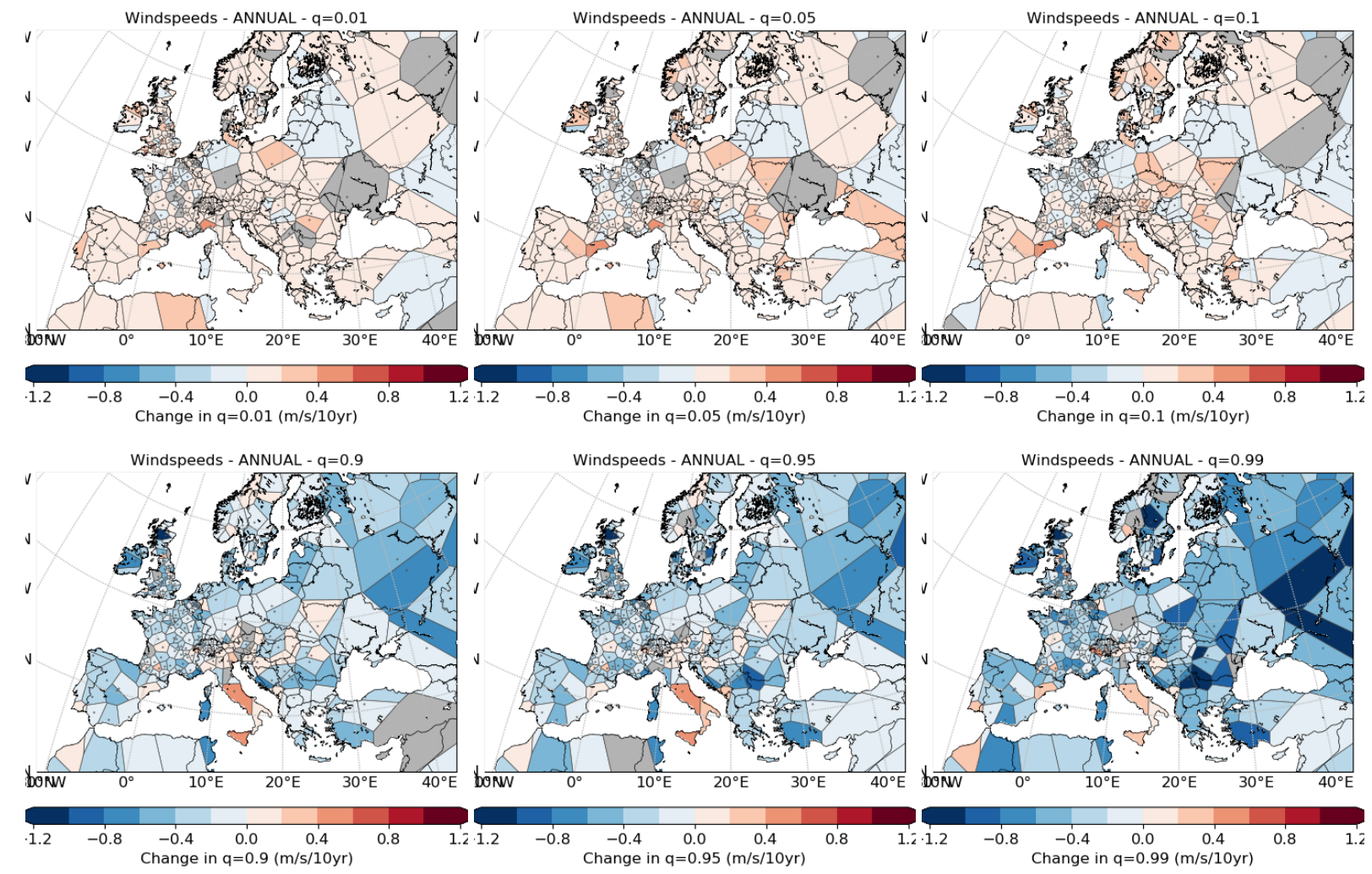

Figure S44. Trend over 1973-2017 in quantiles of wind speed $\left(\mathrm{m} \mathrm{s}^{-1}\right.$ decade $\left.^{-1}\right)$ at тOP 0.01, 0.05 and 0.10; and вотTOM 0.90, 0.95, 0.99 over Europe (annual). 